\title{
Global Atmospheric Teleconnections and Multidecadal Climate Oscillations Driven by Southern Ocean Convection ${ }^{\infty}$
}

\author{
ANNA CABRÉ \\ Department of Physical and Technological Oceanography, Institute of Marine Sciences, Barcelona, Spain, and Department \\ of Earth and Environmental Science, University of Pennsylvania, Philadelphia, Pennsylvania \\ IRINA MARINOV \\ Department of Earth and Environmental Science, University of Pennsylvania, Philadelphia, Pennsylvania \\ ANAND GNANADESIKAN \\ Department of Earth and Planetary Science, Johns Hopkins University, Baltimore, Maryland
}

(Manuscript received 29 October 2016, in final form 15 May 2017)

\begin{abstract}
A 1000-yr control simulation in a low-resolution coupled atmosphere-ocean model from the Geophysical Fluid Dynamics Laboratory (GFDL) family of climate models shows a natural, highly regular multidecadal oscillation between periods of Southern Ocean (SO) open-ocean convection and nonconvective periods. It is shown here that convective periods are associated with warming of the SO sea surface temperatures (SSTs), and more broadly of the Southern Hemisphere (SH) SSTs and atmospheric temperatures. This SO warming results in a decrease in the meridional gradient of SSTs in the SH, changing the large-scale pressure patterns, reducing the midlatitude baroclinicity and thus the magnitude of the southern Ferrel and Hadley cells, and weakening the SO westerly winds and the SH tropical trade winds. The rearrangement of the atmospheric circulation is consistent with the global energy balance. During convective decades, the increase in incoming top-of-the-atmosphere radiation in the $\mathrm{SH}$ is balanced by an increase in the Northern Hemisphere $(\mathrm{NH})$ outgoing radiation. The energy supplying this increase is carried by enhanced atmospheric transport across the equator, as the intertropical convergence zone and associated wind patterns shift southward, toward the anomalously warmer $\mathrm{SH}$. While the critical role of the $\mathrm{SO}$ for climate on long, paleoclimate time scales is now beyond debate, the strength and global scale of the teleconnections observed here also suggest an important role for the SO in global climate dynamics on the shorter interannual and multidecadal time scales.
\end{abstract}

\section{Introduction}

Significant research has focused on the tropical atmospheric teleconnections generated by SST variability in the extratropical North Atlantic and Pacific Ocean [summarized in a review by Chiang and Friedman (2012)], but far less attention has been paid to atmospheric anomalies of Southern Ocean (SO) origin. Observational literature suggests that Southern Ocean temperatures may have varied substantially over

Supplemental information related to this paper is available at the Journals Online website: http://dx.doi.org/10.1175/ JCLI-D-16-0741.s1.

Corresponding author: Anna Cabré, cabre@icm.csic.es decadal (Cook et al. 2000), centennial (Le Quesne et al. 2009), and millennial time scales (e.g., Shevenell et al. 2011). Moreover, climate models often show significant variability in SO temperatures, and recent work (de Lavergne et al. 2014) suggests that this variability may affect how we interpret the impact of global warming in such models. In this paper, we examine the global climate signature of large changes in Southern Ocean temperatures driven by self-sustained variability in deep open-ocean convection.

The current generation of Earth system models [phase 5 of the Coupled Model Intercomparison Project (CMIP5); Taylor et al. 2012] preferentially form deep water through open-ocean convection-rather than on the shelves, as observed-in both the Ross and the Weddell gyres (Heuze et al. 2013; Sallée et al. 2013; de 
Lavergne et al. 2014). Most models cannot properly simulate the formation of deep waters on shelves driven by processes such as dense overflow plumes due to insufficient spatial resolution to resolve boundary layer slopes. Winton et al. (1998) show that in the levelcoordinate models used in almost all CMIP5 models, a resolution of the order of $30-50 \mathrm{~m}$ in the vertical and $3-5 \mathrm{~km}$ in the horizontal would be needed to accurately represent such overflow plumes, a prohibitive resolution for climate simulations that require thousands of years for equilibrium runs. Instead, in climate models wintertime cooling and salinification of SO surface waters can result in the creation of density instability (Gordon 1991), triggering deep-reaching convection and an open-ocean polynya. Although such open-sea convective mixing does not appear to have been the main path to produce deep waters in recent decades, it has been observed in events such as the large $\left(\sim 250000 \mathrm{~km}^{2}\right)$ Weddell Sea polynya of the 1970s, which persisted throughout three consecutive years (e.g., Gordon 1978; Martinson et al. 1981; Gordon 1982), and more regularly on a small, week-long scale (Gordon 2014).

In climate models, this open-ocean convective process occurs as a natural oscillation in the atmosphere-ocean system, with different frequencies and durations of convection across 25 of the 33 CMIP5 ESMs under preindustrial forcing (de Lavergne et al. 2014). The causes and mechanisms behind these oscillations are likely to be very different across various climate models and have only been studied, to our knowledge, in the Kiel climate model (Park and Latif 2008; Martin et al. 2013; Latif et al. 2013; Martin et al. 2015) and in several versions of the GFDL (Geophysical Fluid Dynamics Laboratory) coupled climate model (Galbraith et al. 2011; Bernardello et al. 2014a; Zanowski et al. 2015). In the Kiel model, variability in sea ice plays a critical role, and it is the slow heat accumulation below the thermocline-advected southward by the Atlantic meridional overturning circulation (AMOC) - that eventually destabilizes the water column, driving centennial oscillations of open ocean deep convection in the Atlantic sector of the Southern Ocean (Martin et al. 2013). By contrast, in GFDLESM2M the periodic lateral advection of anomalously salty water into the Weddell Sea triggers the start of open-ocean deep convection (Galbraith et al. 2011) and drives multidecadal oscillations. However, the source of such salty water anomalies remains unclear, and the feedbacks between changes in convection and global climate have not been studied in detail.

Sites of deep open-ocean convection have the potential to play an important climatic role via the oceanic and atmospheric propagation of anomalies generated in the Southern Ocean. In the ocean, active mixing results in a release of accumulated heat to the atmosphere that warms the surface, opens a polynya, and cools the subsurface ocean. This deep ocean cooling signal spreads from the Weddell Sea 1) northward into the Atlantic basic as a deep western boundary current and 2) eastward and westward to the rest of the Southern Ocean and farther north into the subtropical and tropical $\mathrm{Pa}$ cific and Indian basins in the form of both fast wavelike signals and slower advective/diffusive signals, as recently studied by Zanowski et al. (2015) in the GFDLESM2G model. Moreover, SO convective mixing has a significant impact on the AMOC in the Kiel model (Martin et al. 2015). Active SO mixing has also been shown to affect the state of the atmosphere through ocean-to-atmosphere moisture and heat losses, and topof-the-atmosphere (TOA) changes, which lead to rapid warming of the air above a polynya, SST variability, and a successive modification in mesoscale atmospheric motions (e.g., Dethleff 1994; Gallée 1997). Latif et al. (2013) used the Kiel model to report on the atmospheric propagation of SST anomalies that originate in the Weddell Sea convective zones. They showed that during convective phases, the Southern Ocean warms, the sea ice coverage shrinks, and the westerly winds weaken.

Until recently, most studies of tropical-extratropical interaction posit that the tropics drive the extratropics, largely via atmospheric teleconnection patterns such as El Niño-Southern Oscillation (ENSO) (e.g., White and Peterson 1996; Yuan et al. 1996; Peterson and White 1998; Yuan and Martinson 2000; Venegas and Drinkwater 2001). More recently, however, emerging work has used data and climate models to show how the extratropics can be efficient in driving changes in the tropics. For example, an imposed cooling in the northern extratropics results in a southward shift of the ITCZ (Chiang et al. 2003; Chiang and Bitz 2005; Broccoli et al. 2006; Cheng et al. 2007; Chiang et al. 2008; Chiang and Friedman 2012).

Here we use a long control simulation in CM2Mc, a low-resolution coupled climate model from the GFDL family of models that has a strong and regular SO mode of variability (Bernardello et al. 2014a; Seviour et al. 2016; A. Gnanadesikan and M. Pradal 2017, unpublished manuscript; see more details in section $2 \mathrm{~b}$ ). This regularity facilitates the understanding of teleconnections originating in the $\mathrm{SO}$ as separate from the oscillations that originate in other extratropical areas (such as the $\mathrm{NH}$ ) or in tropical regions. We analyze the large-scale changes in atmospheric circulation associated with convective variability in the CM2Mc model (inspired by work in the Kiel model; Latif et al. 2013) and study the changes and variability in the global energy balance (inspired by recent atmospheric work; e.g., Marshall et al. 2014; Donohoe et al. 2014). We find that 
changes in SO deep ocean convection have large and fast implications for both the extratropics and the tropics, producing significant changes in atmospheric temperatures, speed of the westerlies, the Hadley cell, interhemispheric temperature difference, atmospheric transport of energy at the equator, and the position of the intertropical convergence zone (ITCZ). Based on the mechanisms observed, we propose that observed past changes and expected future changes in SO SSTs might similarly have significant global atmospheric and climate implications.

\section{Methodology}

\section{a. Energy balance calculation}

The key diagnostics we use to understand the impact of convective changes here are the transports of energy in the atmosphere $F_{A}$ and ocean $F_{O}$ and their divergences $\nabla \cdot F_{A}$ and $\nabla \cdot F_{O}$. Following previous literature (e.g., Trenberth and Solomon 1994; Zhang and Rossow 1997; Trenberth et al. 2002), the net column change in atmospheric energy is balanced by the TOA radiation and by the surface fluxes. We assume that changes in the storage of mass, moisture, and energy are sufficiently small that they can be neglected (this is generally true for averages of a year or longer; the magnitude of these tendency terms should diminish with the length of the time averaged). Therefore, the divergence of the vertically integrated atmospheric energy transport for a vertically integrated air column can be written as

$$
\begin{aligned}
\left.\nabla \cdot F_{A}\right|_{\text {total }} & =R_{\mathrm{TOA}}-R_{S}+L E+\Phi_{\text {Sens }}^{A}-\text { Storage } \\
& =R_{\mathrm{TOA}}-F_{\text {atm } \rightarrow \text { ocean }}-\text { Storage },
\end{aligned}
$$

where $R_{\mathrm{TOA}}$ is the incoming net radiation at the top of the atmosphere directed downward, $R_{S}$ is the air to ocean radiative heat flux [which includes incoming and outgoing shortwave (SW) and longwave (LW) radiation], $L$ is the latent specific heat of condensation, $E$ is the surface evapotranspiration, $\Phi_{\text {Sens }}^{A}$ is the sensible heat flux to the atmosphere, and Storage is the storage of heat in the atmosphere. We ignore here frictional heating arising from dissipation of kinetic energy. Integrating over the Southern Hemisphere area $(d A)$ and ignoring the storage terms (negligible on an annual mean basis), the northward atmospheric heat transport at the equator is

$T_{\mathrm{Eq}}^{A}=\left.\iint_{\mathrm{SH}} \nabla \cdot F_{A}\right|_{\text {total }} d A=\iint_{\mathrm{SH}}\left(R_{\mathrm{TOA}}-F_{\mathrm{atm} \rightarrow \text { ocean }}\right) d A$.

Similarly, we can calculate the cross-equatorial atmospheric heat transport as

$$
T_{\mathrm{Eq}}^{A}=\iint_{\mathrm{SH}}\left(\Phi_{\mathrm{SW}}^{A}+\Phi_{\mathrm{LW}}^{A}+L E+\Phi_{\mathrm{Sens}}^{A}\right) d A,
$$

where $\Phi_{S W}^{A}, \Phi_{L W}^{A}$ are the net shortwave and long wave fluxes into the atmosphere.

We can separate the total cross-equatorial atmospheric energy transport into two parts, one due to the dry static transport,

$$
\begin{aligned}
T_{\mathrm{Eq}}^{\mathrm{dry}} & =\left.\iint_{\mathrm{SH}} \nabla \cdot F_{A}\right|_{\mathrm{dry}} d A \\
& =\iint_{\mathrm{SH}}\left(R_{\mathrm{TOA}}-R_{S}+L P+\Phi_{\mathrm{Sens}}^{A}\right) d A,
\end{aligned}
$$

and one due to the net transport of water vapor, also known as latent energy transport,

$$
T_{\mathrm{Eq}}^{\text {latent }}=\left.\iint_{\mathrm{SH}} \nabla \cdot F_{A}\right|_{\text {water vapor }} d A=\iint_{\mathrm{SH}} L(E-P) d A,
$$

where $P$ represents the precipitation rate.

If energy is used to evaporate water at location A and the vapor is transported to location B where it condenses, releasing the heat of condensation, energy has been transported from A to B via latent heat transport. This latent heat transport plays a critical role in the total atmospheric heat transport. In the deep tropics within $20^{\circ} \mathrm{N} / \mathrm{S}$, the atmospheric heat transport due to water vapor acts against the dry air heat transport, reducing the net atmospheric heat transport from low to high latitudes.

The total northward oceanic heat transport at the equator, $T_{\mathrm{Eq}}^{O}$ can be calculated as the integral of all heat fluxes entering the ocean (from the atmosphere) in the $\mathrm{SH}$, minus the ocean heat stored in the $\mathrm{SH}$, which is significant and cannot be neglected. The storage is calculated as the time derivative of the heat content in the ocean:

$$
\begin{aligned}
T_{\mathrm{Eq}}^{O} & =\left.\iint_{\mathrm{SH}} \nabla \cdot F_{O}\right|_{\text {total }} d A \\
& =\iint_{\mathrm{SH}}\left(F_{\text {atm } \rightarrow \text { ocean }}-\text { Storage }_{\text {ocean }}\right) d A .
\end{aligned}
$$

\section{b. Model details and biases}

All simulations were conducted using the GFDL Climate Model version 2 with Modular Ocean Model version $4 \mathrm{p} 1$ at coarse resolution (CM2Mc) (Galbraith et al. 2011). The code for oceanic and atmospheric physics in CM2Mc is based on the GFDL Earth System Model with the Modular Ocean Model (ESM2M) (Dunne et al. 2012), but slightly adapted to fit to the coarser resolution. The resolution of the ocean module is approximately $3^{\circ} \times$ $2^{\circ} \times 28$ vertical levels. CM2Mc is initialized as shown in 
(a) Precipitation rate climatology ( $\mathrm{mm} /$ day)

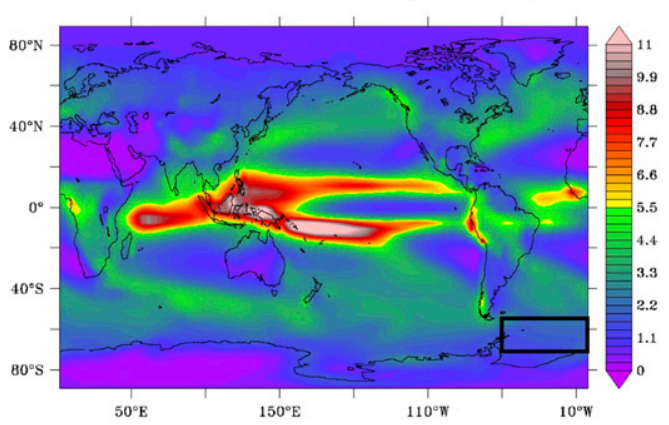

(c) Convective - Non Convective Decades Precipitation rate $(\mathrm{mm} /$ day)

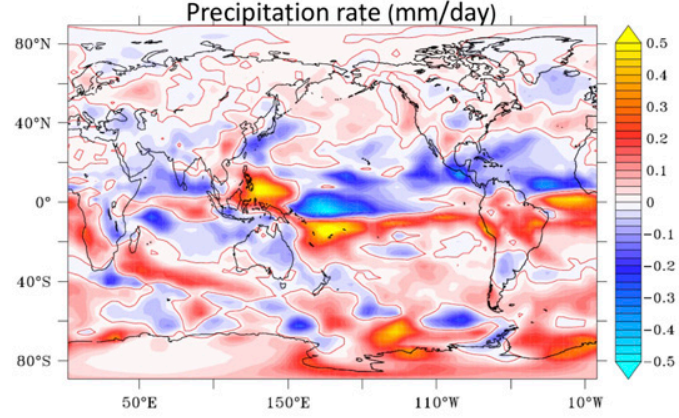

(b) Column-Integrated Water vapor concentration

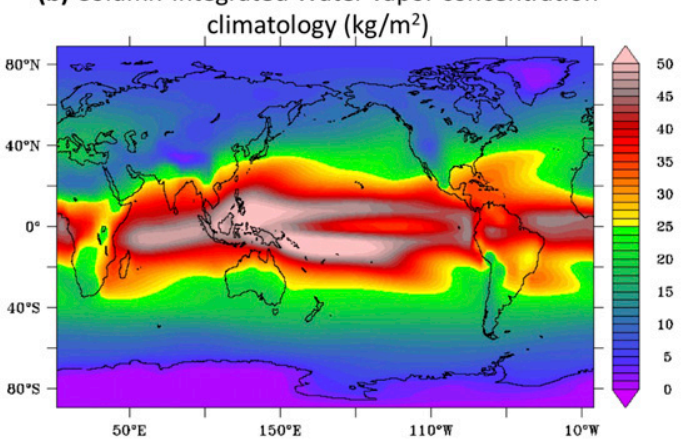

(d) Convective - Non Convective Decades Column-Integrated Water vapor concentration $\left(\mathrm{kg} / \mathrm{m}^{2}\right)$

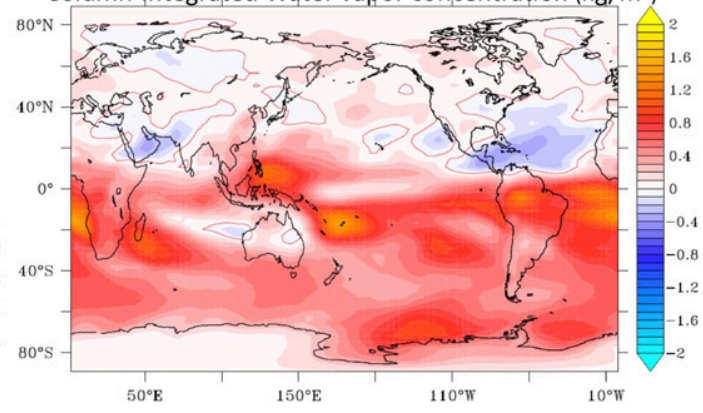

FIG. 1. (a),(b) Climatology map and (c),(d) composites, i.e., difference between convective and nonconvective decades, for precipitation rate and column-integrated water vapor concentration as labeled. Climatology and composites are calculated from 500 years of the control simulation. The Weddell Sea is defined as $60^{\circ} \mathrm{W}-0$ and $55^{\circ} \mathrm{S}-$ $70^{\circ} \mathrm{S}[\mathrm{box}$ in $(\mathrm{a})]$.

Galbraith et al. (2011) and spun up for 4500 years with preindustrial conditions (where greenhouse gases, aerosols, and ozone are kept at the value of year 1860) as described in Bernardello et al. (2014a,b).

The net radiative balance in the CM2Mc model is qualitatively consistent with observations, with net incoming radiation in the $\mathrm{SH}$, net outgoing radiation in the $\mathrm{NH}$, and a total interhemispheric heat transport that is (realistically) northward. However, our model has the common double-ITCZ bias, in which excessive precipitation is produced in the SH tropics in a band that looks like the southern counterpart to the strong northern ITCZ (Fig. 1a). This significant and highly persistent bias in global climate models has most recently been related to large cloud biases over the Southern Ocean that allow too much incoming shortwave radiation (e.g., Hwang and Frierson 2013). In the CM2Mc model, the SW absorption is about $4 \mathrm{~W} \mathrm{~m}^{-2}$ larger in the $\mathrm{SH}$ than in the $\mathrm{NH}$, likely due to insufficient cloudiness over the Antarctic as observed in GFDL models (e.g., Delworth et al. 2006). This anomalous SO heat is transported to the tropics by baroclinic eddies and is carried out in the tropical region via thermodynamic air-sea coupling, for example, the windevaporation-SST feedback (Mahajan et al. 2011; Kang et al. 2014; Li and Xie 2014). The bias ultimately results in intensified cross-equatorial northward transport of heat and intensified cross-equatorial southward transport of water vapor in the lower troposphere, triggering an excess in precipitation in the tropical SH (Hwang and Frierson 2013). In the CM2Mc model, the resulting rise in SH temperatures does not produce enough of a rise in outgoing longwave radiation to balance this bias in net SW heating, and the SH remains warmer than the NH by $0.8^{\circ} \mathrm{C}$ (surface air annual mean temperature), contrary to observations showing a NH warmer than the $\mathrm{SH}$ by $1.24^{\circ} \pm 0.16^{\circ} \mathrm{C}$ (Kang et al. 2015).

While in an average of 24 CMIP3 models the NH is warmer than the $\mathrm{SH}$ by $1.13^{\circ} \mathrm{C}$ (Meehl et al. 2007), which is close to observations, there is a large spread of interhemispheric temperature and precipitation differences and cross-equator heat transport differences across climate models. Across CMIP5 models, Hwang and Frierson (2013) showed that a warmer SH (relative to the $\mathrm{NH}$ ) is generally associated with 1 ) higher tropical precipitation in the $\mathrm{SH}$ (relative to the $\mathrm{NH}$ ) and hence a larger double-ITCZ bias, and 2) a more northward atmospheric cross-equatorial heat transport.

These biases also imply that the NH Hadley cell spends more time in the $\mathrm{SH}$ than observed, so the ascending branch of the Hadley cell is on average centered 

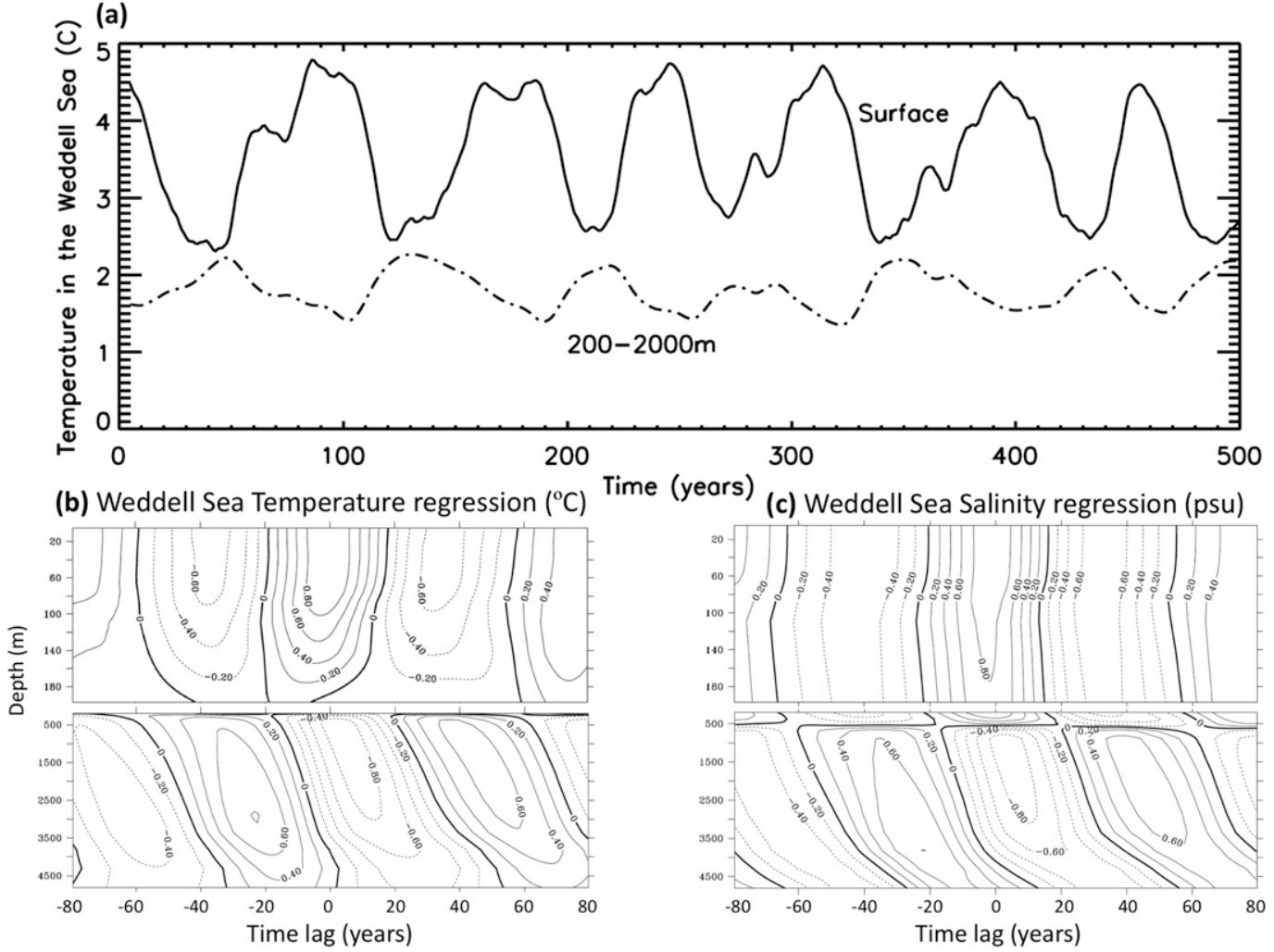

FIG. 2. (a) Time series of the Weddell Sea temperature at the surface and at intermediate depths in the control $\mathrm{CM} 2 \mathrm{Mc}$ simulation. The Weddell Sea is defined as the zone comprising $60^{\circ} \mathrm{W}-0^{\circ}$ and $55^{\circ}-70^{\circ} \mathrm{S}$ (see box in Fig. 1a). Also shown are lagged regression coefficient of Weddell Sea depth profile of (b) temperature and (c) salinity vs the convection index time series. Negative (positive) values on the time axis indicate periods before (after) a maximum in convection (at lag 0 ).

in the SH. As we will see later, however, in our model the net atmospheric transport of heat is southward, the opposite of what we would expect from a tropical atmospheric circulation dominated by the NH Hadley cell. This is the result of rectification of a seasonal signal, as the SH Hadley cell is more effective at transporting heat southward across the equator when it extends into the Northern Hemisphere than the NH Hadley cell is in transporting heat northward when it extends into the Southern Hemisphere. This seasonal rectification remains basically unchanged throughout the run. However, changes in heat transport associated with changes in the strength of the Hadley cells do follow our intuition that more clockwise ( $\mathrm{NH}$ centered) circulations will transport more heat northward.

\section{Main results}

\section{a. Open-sea Southern Ocean convection and implications for temperature}

Open-ocean convection in the Weddell Sea releases large amounts of heat into the atmosphere approximately every 75 years in the CM2Mc model (Figs. 2a,b). The onset of convection is associated with a sharp rise in SSTs and a decline in middepth ocean temperatures (Fig. 2a) as heat accumulated during nonconvective decades is released to the surface ocean and atmosphere. Active mixing also results in increased salinity at the surface and anomalous freshening in the deep ocean (Fig. 2c). As convection stops in the Weddell Sea, the water column becomes stratified, isolating the surface layers from the warmer and saltier water mass below, such that the surface cools and freshens and the deeper ocean warms and gets saltier (Figs. 2b,c). The formation of $\mathrm{AABW}$ is then inhibited. Convective periods are slightly longer than nonconvective periods, which can be seen in the asymmetry of the middepth temperature signal in Fig. 2a.

Figure 2a shows that we can use the SST in the Weddell Sea or the middepth temperature (200-2000 m) as indices of Southern Ocean convective activity (those time series have been smoothed with a 10 -yr running mean). We use middepth temperature to build composite maps of nonconvective (average over time steps 
(a) Composite air surface temperature AST $\left({ }^{\circ} \mathrm{C}\right)$

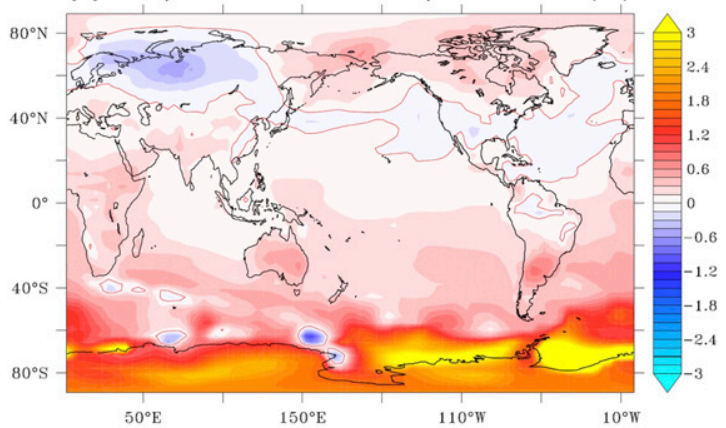

(b) Composite air temperature height profile $\left({ }^{\circ} \mathrm{C}\right)$

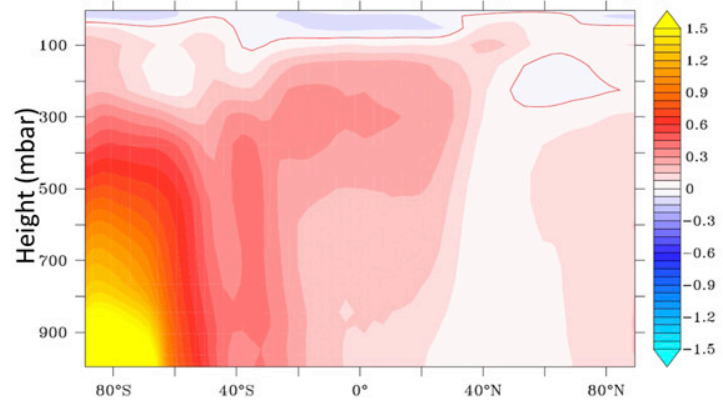

(c) Lagged regression AST on convection index

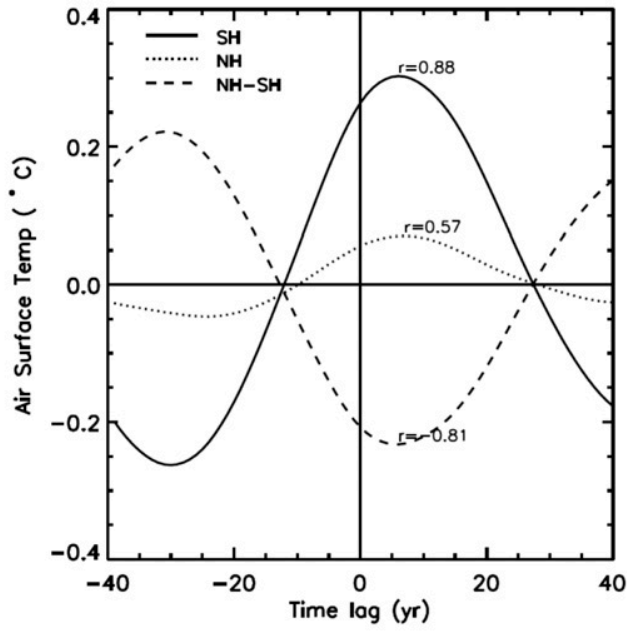

FIG. 3. Composite difference between convective and nonconvective decades for (a) air sea surface temperature and (b) longitude-averaged height profile of air temperature. The composites are calculated from a 500-yr control simulation. (c) Lagged regression between the convection index and the averaged air sea temperature in the $\mathrm{SH}$ and $\mathrm{NH}$, and the hemispheric difference. The correlation $r$ is labeled where it is maximum. Negative (positive) values on the time axis indicate periods before (after) a maximum in convection (located at lag 0 ).

with temp $>1.9^{\circ} \mathrm{C}$ ) and convective (temp $\left.<1.7^{\circ} \mathrm{C}\right)$ decades (e.g., Figs. 3a,b) and use the more sinusoidal SST curve to calculate lagged regressions (as in Fig. 3c). From now on, we call convection index to the Weddell SST normalized from -1 to 1 . First, we subtract the average from the SST time series, and then we divide by the new maximum value. The convection index has a value of 1 at the peak of the strongest convective event (and approximately -1 at the peak of nonconvection). The choice of convection index is somewhat arbitrary, but our conclusions presented here hold when using other indices. For example, we have also defined convective years when the yearly-averaged mixed layer depth (MLD) is deeper than $60 \mathrm{~m}$ (MLD is here defined as the depth where the density difference to the surface is $0.125 \mathrm{~kg} \mathrm{~m}^{-3}$ ) and found similar conclusions. The onset of convection and heat content is also well defined by the age tracer used in our model—whose value increases as a parcel is submerged and is reset to zero when a parcel reemerges at the surface-as subsurface SO age drops suddenly when convection starts. Bernardello et al. (2014a) present a more detailed description of the convective events in the CM2Mc model and their impact on the carbon cycle.
Following a convective event, both SSTs and surface air temperatures increase in the Southern Hemisphere (Figs. 3a,c), particularly south of $40^{\circ} \mathrm{S}$ with the largest changes in the Weddell Sea (Fig. 3a). The maximum SH warming anomaly is reached $\sim 7$ years after the peak in SSTs in the Weddell Sea (Fig. 3c). Surface air temperature (Fig. 3a) and SSTs also show warming in most of the Northern Hemisphere with a similar time delay but less intensity than in the SH (Fig. 3c). Hence, convective decades result in a more negative north-south interhemispheric air surface temperature asymmetry (Fig. 3c), which has consequences for the position of the intertropical convergence zone in the tropics, as we will discuss in section $3 \mathrm{~d}$. This strong surface warming in the Southern Ocean propagates to the rest of the atmosphere almost instantaneously, although the signal loses intensity away from the Weddell Sea (Fig. 3b).

\section{b. Implications for the extratropical atmosphere above the Southern Ocean}

The Ferrel cell, the meridional mean circulation associated with the midlatitudes, can be thought of as the result of baroclinic instability of the midlatitude jet. As baroclinic instability releases potential energy by 
flattening potential temperature surfaces that slope upward toward the pole, more heat is brought to high latitudes and momentum is fluxed down toward the surface, decelerating the jet aloft and increasing westerlies near the surface. The jet aloft is maintained by the propagation of eddies away from the jet, which produces an eddy flux of momentum back into the jet. Limpasuvan and Hartmann (2000) show that increased baroclinicity associated with the southern annular mode tends to increase both the flux of momentum into the jet aloft and its downward redistribution in the vertical, resulting in an increase in the surface westerlies. Coincident with this they see an increase in the poleward flux of heat.

In our model results, the onset of convection in the Weddell Sea warms the surface around $60^{\circ} \mathrm{S}$ most strongly, which weakens the meridional contrast in SSTs between $45^{\circ}$ and $60^{\circ} \mathrm{S}$. We argue that this translates into a weaker southern Ferrel cell (Figs. 4b,c), weaker westerlies over the SO (Fig. 5b), and a transition toward a weaker (more negative) southern annular mode (SAM) phase (Fig. 5c). As zonal mean atmospheric temperatures warm over the cold Antarctic latitudes more than in the tropics (Fig. 3b), atmospheric baroclinicity in the $\mathrm{SH}$ midlatitudes decreases. As a result, we see a concomitant decrease in the Ferrel cell (Figs. 4b,c) with the peak decrease lagging the peak in Weddell Sea temperatures, just as the SH SSTs lag the convection within the Weddell Sea (Fig. 3c). The air moving poleward in baroclinic disturbances tends to move eastward in the Southern Hemisphere, creating the SH westerlies (Fig. 5a). During convective decades, decreases in the atmospheric baroclinicity in the midlatitudes result in a decreased poleward eddy transport of eastward momentum into the midlatitudes via large-scale Rossby waves, decreasing and shifting equatorward the near-surface westerlies (Fig. 5b). The northward shift in westerlies is also nicely reflected in the Ekman vertical velocities in the Southern Ocean, with a band of decreased upwelling south of $50^{\circ} \mathrm{S}$ (see Fig. S1 in the online supplemental material). The surface pressure shows a distinctive pattern of increasing (decreasing) pressures roughly south of $60^{\circ} \mathrm{S}$ (north of $60^{\circ} \mathrm{S}$ ) (Fig. 5c). Hence, the southern annular mode-defined as the pressure difference between $40^{\circ}$ and $60^{\circ} \mathrm{S}$-decreases during convective years. It is worth noting that the extratropical response to SO convection, a weakening of westerly winds and a transition toward negative SAM, is consistent with that of stratospheric ozone-hole recovery (Son et al. 2008; Kang et al. 2011).

The changes in temperature structure are also associated with changes in cloudiness (Fig. 6). In particular, convective decades are associated with a strong decrease in low clouds and slight increase in high clouds over the Southern Ocean. Interdecadal correlations between warm anomalies in SSTs and increases (decreases) in high (low) cloud behavior were previously shown for the northeast subtropical Pacific in observations (Clement et al. 2009) as well as in the GDFL model (Broccoli and Klein 2010; Clement et al. 2010). The basic physics underlying this is that low clouds require a temperature inversion layer to trap moisture within the atmospheric boundary layer. Wood and Bretherton (2006) demonstrate that the strength of this inversion is positively correlated with low cloud amount because such inversions prevent plumes leaving the moist surface from reaching the upper troposphere and forming high clouds, and keep the relative humidity high at the top of the boundary layer where low clouds form. In the presence of open ocean convection in CM2Mc, the inversion at the top of the boundary layer weakens. The boundary layer becomes warmer and moister such that the moist potential temperature gradient between 700 and $1000 \mathrm{mb}$ becomes smaller by up to $3^{\circ} \mathrm{C}$. The low cloud amount drops by up to $12 \%$ locally, with highest decreases over the Atlantic and Pacific SO south of $60^{\circ} \mathrm{S}$ (Fig. 6f).

The increased cumulus mass flux associated with a more unstable boundary layer both moistens and warms the upper atmosphere. All else being equal, the moistening of the upper atmosphere tends to increase highlevel cloudiness, while the warming tends to decrease cloudiness. Analysis of the three-dimensional structure of the humidity and temperature fields shows a relatively smooth relative increase in specific humidity throughout the upper atmosphere, but much spatially patchier changes in temperature in the horizontal plane, which may reflect changes in the lower stratospheric circulation. Hence, the changes in high clouds associated with convective decades (Fig. 6e) - in response to compensating effects of humidity and temperature changesshow patterns spatially patchier than low clouds do (Fig. 6f). We defer detailed investigation of these upper troposphere/lower stratospheric changes to future work.

\section{c. Anomalies in the energy balance of the ocean-atmosphere system}

In response to open ocean convective oscillations, the interhemispheric heat transports in the ocean and atmosphere, the TOA radiation, and air-sea fluxes all change on decadal time scales. The schematic in Fig. 7 summarizes the climatological 500-yr mean hemispherically averaged energy budget terms for both the ocean and the atmosphere (solid arrows and values in gray), as well as anomalies in the energy balance terms associated with the maximum in convection (striped 

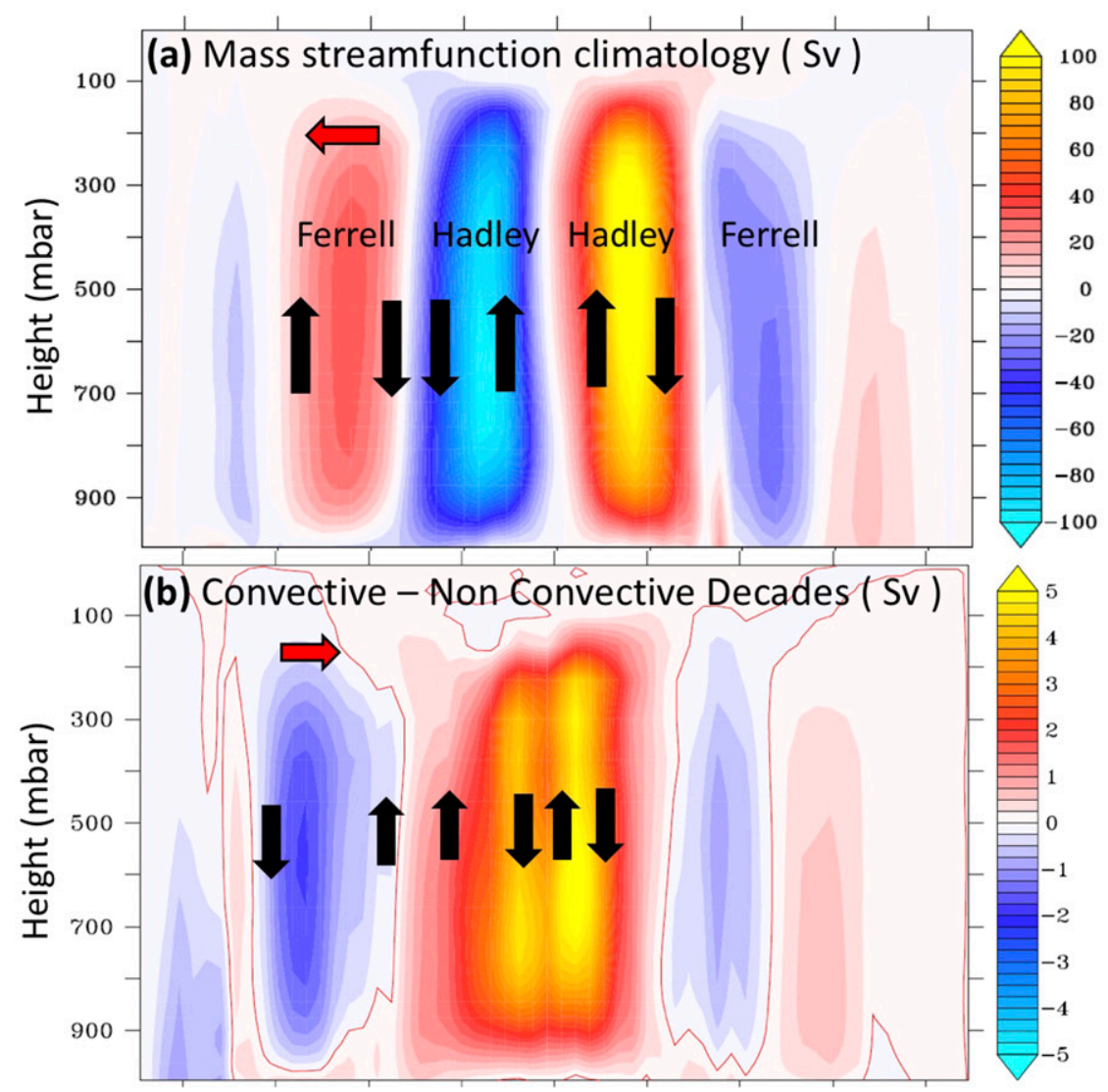

(c) Lagged regression 500 mbar streamfunction ( Sv )

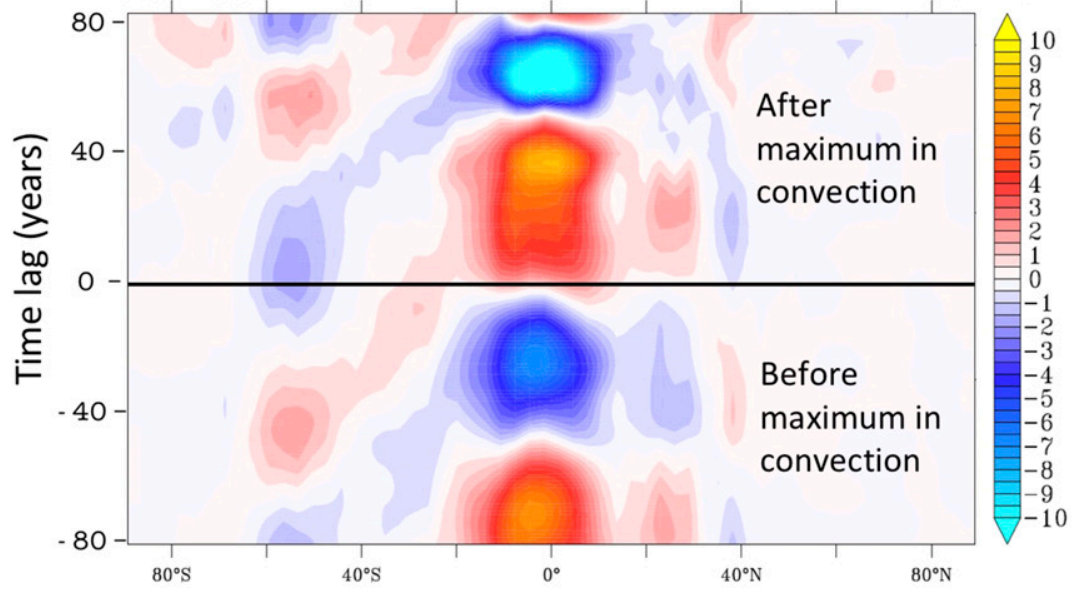

FIG. 4. Atmospheric overturning mass streamfunction: (a)climatology map; (b) composite, i.e., the difference between convective and nonconvective decades from 500 years of the control simulation; and (c) lagged regression of 500-mbar mass streamfunction vs convective index, where negative (positive) values on the time axis indicate periods before (after) a maximum in convection (at lag 0). Black arrows indicate the flow direction of the Hadley and Ferrel cells in (a) and their anomalies in (b). Red arrows indicate the direction of the eddy flux.

arrows and values in parentheses) and $\sim 12$ years later (dotted arrows and values in parentheses). Lagged correlations between the individual terms in the radiative balance and the convective index (Fig. 8) help us understand and complete the detailed energetic dynamics of the two hemispheres summarized in Fig. 7. Figure S2 shows the detailed energy balance at lags of -22 (which approximately coincides with the start of 
(a) Surface zonal wind stress climatology $\left(\mathrm{N} / \mathrm{m}^{2}\right)$

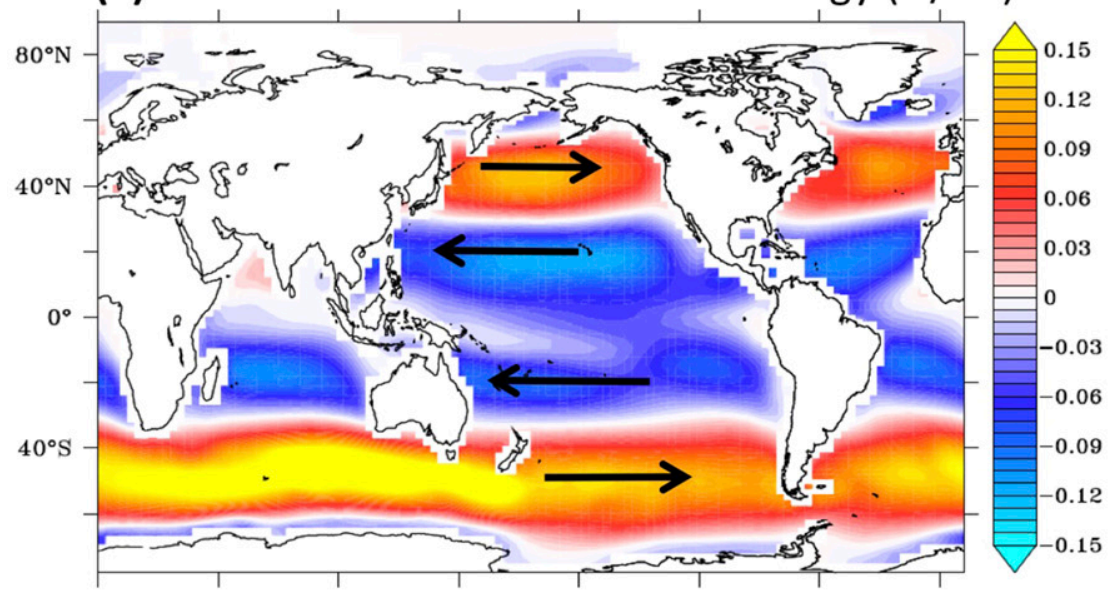

(b) Convective - Non Convective wind stress $\left(\mathrm{N} / \mathrm{m}^{2}\right)$

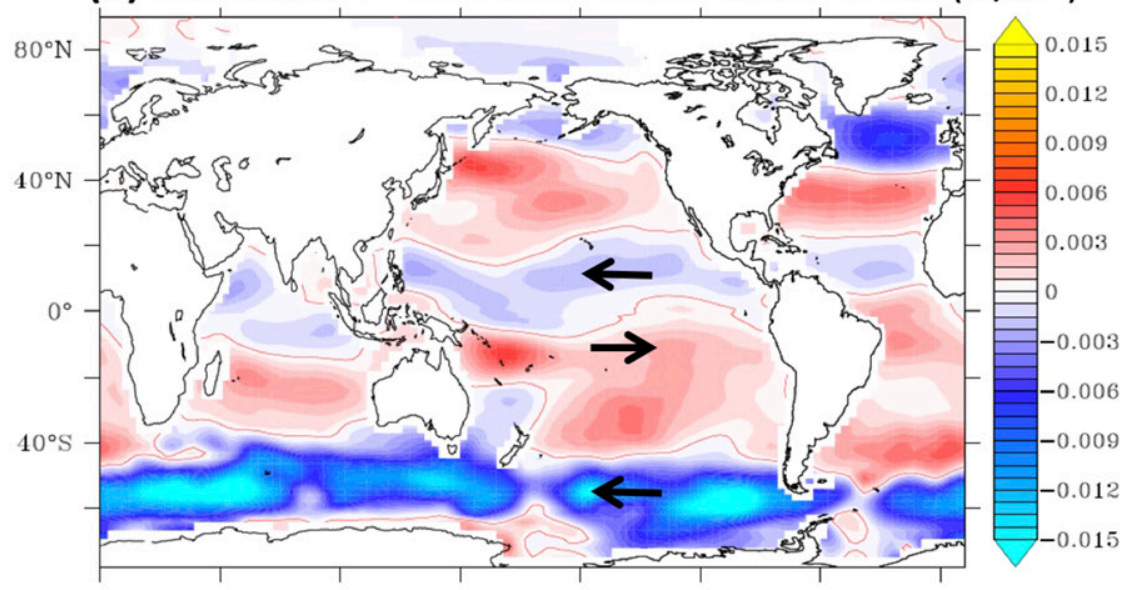

\section{(c) Convective - Non Convective surf pressure (mbar)}

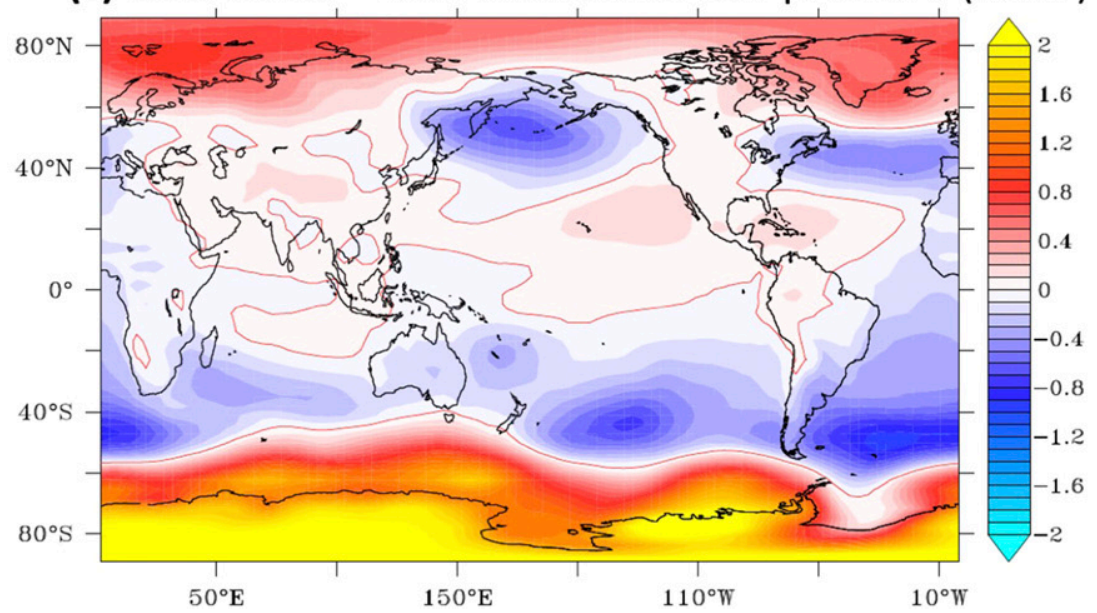

FIG. 5. (a) Climatology map, and composite (difference between convective and nonconvective decades) for (b) zonal wind stress and (c) surface pressure. Climatology and composites are calculated from a 500-yr control simulation. 
(a) Cloud coverage (\%)
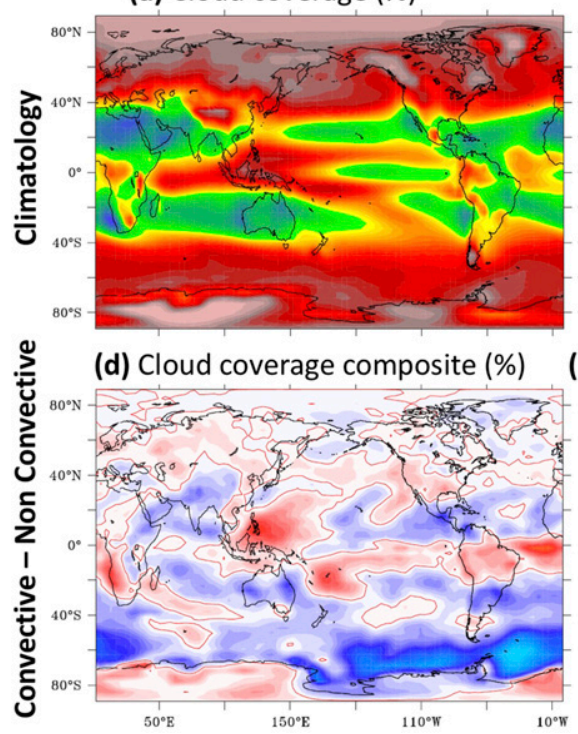

(b) High-Cloud coverage (\%)

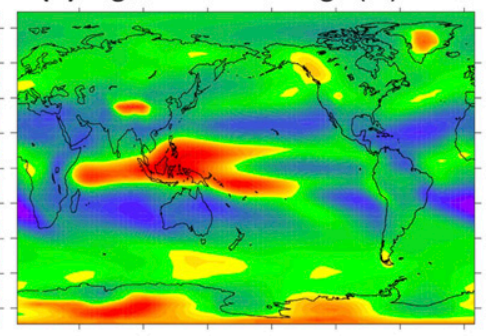

(e) High-Cloud coverage composite (\%)

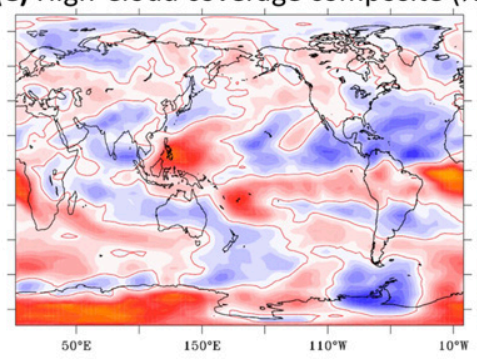

(c) Low-Cloud coverage (\%)

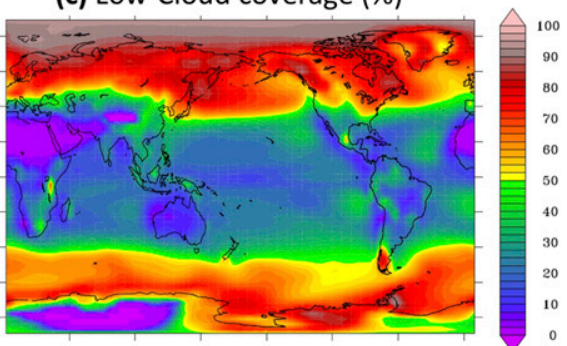

(f) Low-Cloud coverage composite (\%)

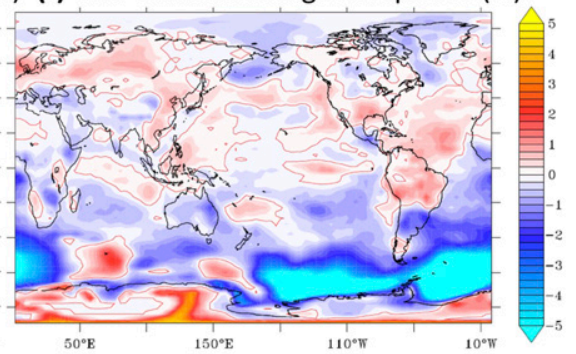

FIG. 6. (a)-(c) Climatology map and (d)-(f) composite (difference between convective and nonconvective decades) for cloud coverage as labeled. Climatology and composites are calculated from a 500-yr control simulation.

convection), 0 (maximum in convection), 12 (zero anomalous net TOA in the SH), 20 (maximum anomalous ocean to atmosphere flux in the $\mathrm{SH}$ ), and 35 years (maximum in nonconvection). We neglect the fluxes to points denoted as land as these contribute less than 5\% to the interdecadal flux anomalies studied in Fig. 7 when hemispherically averaged.

The changes in TOA net fluxes can largely be understood in terms of changes in the spatial distributions of clouds (already shown in Fig. 6) and individual energy balance terms (impacts on individual fluxes are shown in Fig. S3). Broadly speaking, low clouds reflect more the incoming SW radiation, while higher clouds with colder tops emit less outgoing longwave radiation (OLR) to space relative to low clouds. During convective years, an SST-driven decrease in sea ice (which results in lower albedo) combined with decreased low and midlevel clouds as seen in Figs. $6 \mathrm{c}$ and $6 \mathrm{f}$ (lower albedo) results in an increase of the net TOA SW flux into ocean regions south of $60^{\circ} \mathrm{S}$ and particularly in the Weddell Sea (Fig. S3a). The OLR radiation increases over most of the $\mathrm{SH}$, and in large regions in the $\mathrm{NH}$, both on land and in the ocean due to overall warming during convective decades, with most prominent increases south of $60^{\circ} \mathrm{S}$ and over the Weddell Sea (this can be seen as a decrease in LW incoming radiation in Fig. S3b). By contrast, shortwave flux decreases and longwave trapping increases (OLR decreases) in tropical Pacific and Atlantic bands or over the west Pacific warm pool (Figs. S3a-c), with patterns associated with an increase in high clouds during convective decades (Fig. 6e).
When integrated over the Southern Hemisphere, the TOA net incoming SW signal dominates the OLR signal at the peak of convection (Fig. 8a, at lag 0), such that in the net during convective decades there is an overall increase in the TOA incoming radiation of $\sim 0.05 \mathrm{PW}$ over the SH (Fig. 7). Some of this anomalous TOA heat penetrates into the ocean $(\sim 0.02 \mathrm{PW}$; Fig. $8 \mathrm{c})$ and the rest is transported northward through the atmosphere ( $\sim 0.03$ PW; Fig. 8 e), with most of it leaving the atmosphere in the $\mathrm{NH}(\sim 0.02 \mathrm{PW}$ of outgoing TOA radiation in the $\mathrm{NH}$ at lag 0; Fig. 8b).

At the ocean surface, the largest flux changes occur in the convective zone, where a new polynya forms during open-ocean mixing events (Figs. S3d-g). The polynya (ice free) absorbs extra SW radiation during convective decades $\left(\sim 10 \mathrm{~W} \mathrm{~m}^{-2}\right)$ compared to the average ocean state (Figs. S3d and S5a). However, increased LW flux from the ocean to the atmosphere $\left(\sim 10 \mathrm{~W} \mathrm{~m}^{-2}\right)$ and increased evaporative ocean cooling $\left(\sim 5 \mathrm{~W} \mathrm{~m}^{-2}\right)$ result in total heat loss from the ocean to the atmosphere in the polar regions south of $60^{\circ} \mathrm{S}$ (Figs. S3e,f and S5a).When integrated over the $\mathrm{SH}$, the heat loss from the ocean into the atmosphere increases to its maximum value of $0.055 \mathrm{PW}$ approximately 20 years after the peak in convection (Fig. 8c; see also Fig. S2). This lag is mostly due to a lag in evaporative cooling (when integrated over the SH; Fig. S5). The sensible heat flux into the atmosphere decreases on average over the $\mathrm{SH}$ in response to convection, primarily because of a decline in atmospheric wind intensity (Fig. S5).

During the peak in convection (at lag 0), the northward cross-equatorial oceanic heat transport increases 


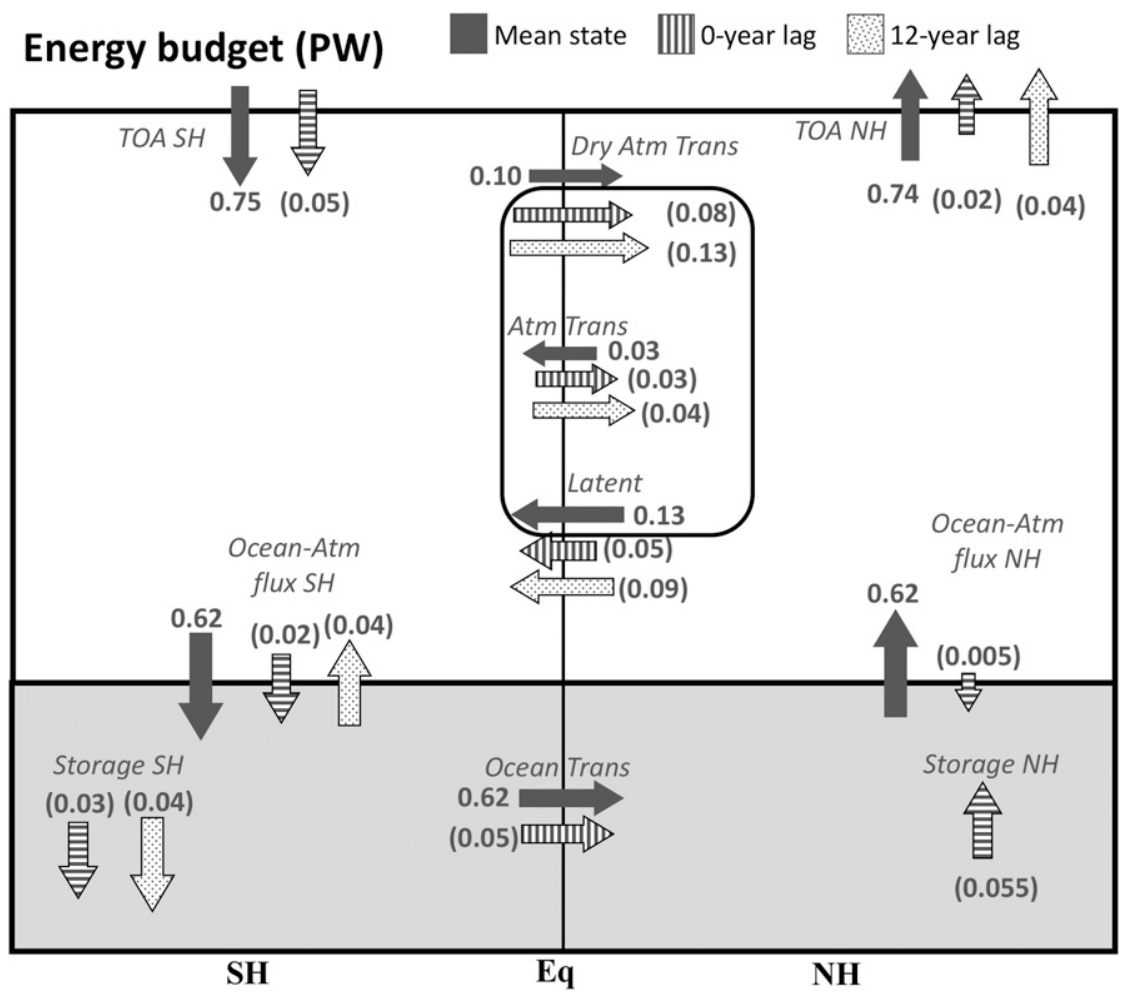

FIG. 7. Summary schematics of the response of the atmosphere-ocean system to Southern Ocean convection. Vertical arrows in each hemisphere show hemispherically averaged fluxes and anomalies; horizontal arrows at the equator show total cross-equatorial fluxes and anomalies. The mean state energy budget is represented by solid arrows, with values in PW. Anomalous heat fluxes and ocean heat storages associated with maximum convection in the Weddell Sea ( 0 -yr lag) are presented as striped arrows, with values in parentheses. Dotted arrows show anomalies $\sim 12 \mathrm{yr}$ after the peak in convection. If no anomalous arrow is shown, the omitted flux is zero. Anomalous heat fluxes and heat storages correspond to the regression coefficient of each variable onto the convective index at the corresponding time lag (as detected in Fig. 8).

by $\sim 0.05 \mathrm{PW}$, as the heat stored in the SH decreases by $\sim 0.03 \mathrm{PW}$ and the heat flux from the atmosphere into the $\mathrm{SH}$ ocean increases by $\sim 0.02 \mathrm{PW}$ (Figs. 7 and $8 \mathrm{c}$ ). This anomalous northward heat transport is mostly stored in the $\mathrm{NH}$ and is not released into the $\mathrm{NH}$ atmosphere (Fig. 7). This can be seen when comparing Figs. $8 \mathrm{c}$ and $8 \mathrm{~d}$ - the intensity $(0.05 \mathrm{PW})$ and pace (i.e., the lagged response to convection) of the ocean heat stored in the NH (Fig. 8d) is almost identical to the heat transported at the equator (Fig. 8c), while the oceanatmospheric heat flux is negligible in the $\mathrm{NH}$ (Fig. 8d) at all times. Hence, most of the changes in TOA radiation in the $\mathrm{NH}$ associated with convection (Fig. 8b) are not propagated from the Southern to the Northern Hemisphere atmosphere through the ocean.

Instead, the anomalous outgoing TOA radiation in the NH (Fig. 8b, solid line) can be explained at all times by anomalous northward atmospheric heat transport (Fig. 8e, solid line). In the NH, the net TOA radiation is mostly dominated by changes in the LW term (Fig. 8b), with increased loss of heat to space during convective decades due to intensified outgoing LW radiative flux (associated with warming). Approximately 12 years after the peak of a typical convective event, the anomalous cross-equatorial atmospheric northward heat transport and outgoing TOA radiation in the $\mathrm{NH}$ are at their maximum $(\sim 0.04 \mathrm{PW}$; Figs. 7 and $8 \mathrm{e})$. These $0.04 \mathrm{PW}$ are transferred from the SH ocean to the atmosphere, while ocean heat stored in the SH decreases by the same amount (Fig. 8c). Note that at a 12-yr lag, there is no anomalous cross-equatorial heat transport in the ocean (Fig. 8c) or anomalous incoming TOA radiation in the SH (Fig. 8a). During the peak of no convection (approximately 35 years after the peak in convection), the anomalies in the energy budget have almost reversed with respect to the anomalies during the peak in convection (see Fig. S2).

If we separate the atmospheric transport into its components due to dry static [Eq. (4)] and water vapor (latent) transport [Eq. (5)], we note that convective 
(a) Incoming TOA radiation $\mathrm{SH}$

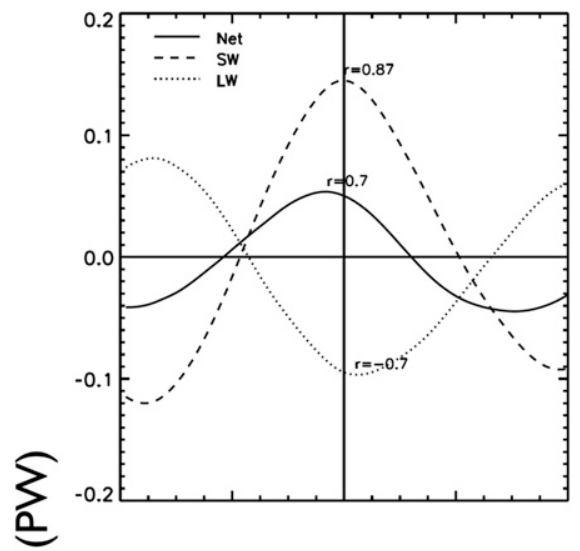

(b) Incoming TOA radiation $\mathrm{NH}$

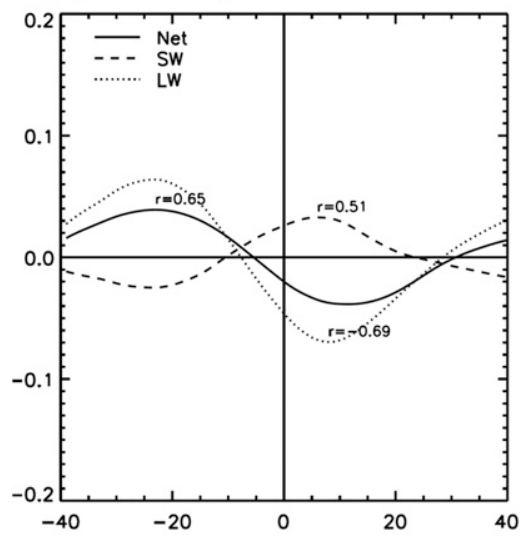

(c) Ocean heat budget $\mathrm{SH}$

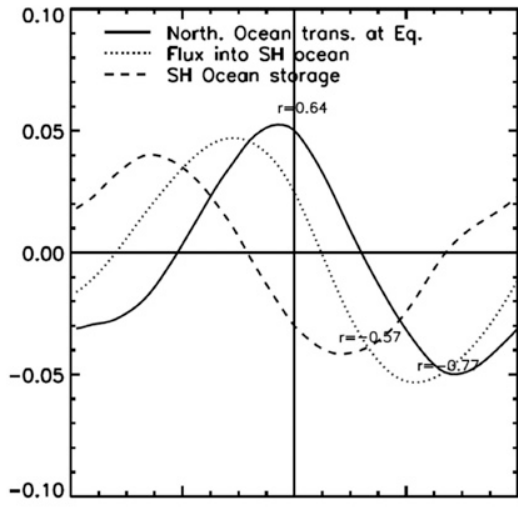

(d) Ocean heat budget NH

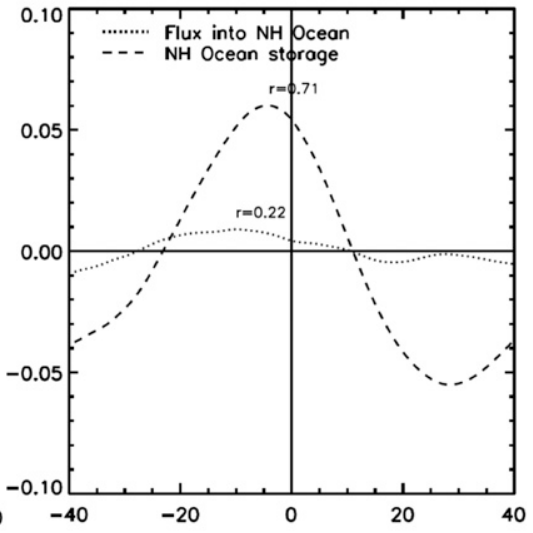

(e) north. Atm. Heat Transp. at Eq.

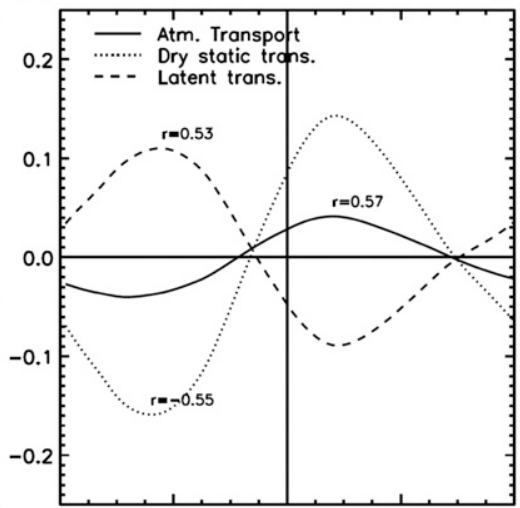

(f) Contributions to northern Atm. Heat Transp. at Equator

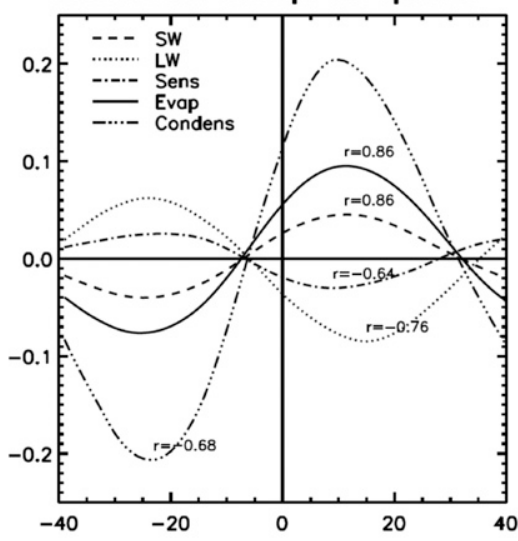

Lagged time from convection peak (years)

FIG. 8. Lagged regressions of different variables onto the Weddell Sea convection index. Variables include (a),(b) incoming TOA SW, LW, and net radiative flux in the two hemispheres; (c),(d) ocean heat budget terms including northward ocean heat transport at the equator, atmosphere-ocean heat flux, and ocean storage in the two hemispheres; (e) northward atmospheric transport at the equator, also separated into dry static and latent heat transport components as in Eqs. (4) and (5); and (f) atmospheric heat transport at the equator separated into the SW, LW, sensible, evaporative, and condensation driven components as in Eqs. (3)-(5). For each variable the maximum correlation $r$ is labeled. For all figures, negative (positive) values on the time axis indicate periods before (after) a maximum in convection is achieved (at lag 0).

decades have more northward dry static energy transport at the equator, partially compensated by a water vapor transport that is more southward during these decades (Fig. 8e). We have also separated the northward atmospheric heat transport at the equator into individual heating terms, reorganizing Eq. (2) into net atmospheric SW and longwave heating, evaporation, and sensible heating transport terms [Eq. (3) and Figs. S3f-i]. At a 12-yr lag, the northward cross-equatorial atmospheric energy transport increases mainly due to evaporation (and evapotranspiration) adding energy to the atmosphere ( $\sim 0.10$ PW in Fig. $8 f)$. The evaporative contribution to northward heat transport follows the Southern Hemisphere air surface temperature pattern (Fig. 3c) in peaking about 12 years after the convection peak. As the temperature and water vapor content of the atmosphere increase with SO convection (Figs. 1b,d and 3a,b), there is also an increase in the amount of SW flux absorbed by the atmosphere in the Southern Hemisphere ( $\sim 0.05$ PW in Fig. 8f; see also Fig. S3h). However, note that most of the increase in net TOA shortwave radiation into the Southern Hemisphere $(\sim 0.15 \mathrm{PW}$ at a 0 -yr lag in Fig. 8a) is due to intensified SW ocean heat uptake (Figs. S3a,d and Fig. 8a vs Fig. S4b) and only a fraction of it is absorbed in the atmosphere (peaking $\sim 12$ years after).

The SW and evaporative atmospheric warming tendencies are counterbalanced (in the $\mathrm{SH}$ average) by longwave cooling $(\sim 0.09 \mathrm{PW})$ and to a secondary extent by a suppression of sensible heat fluxes leaving the ocean 
(a)

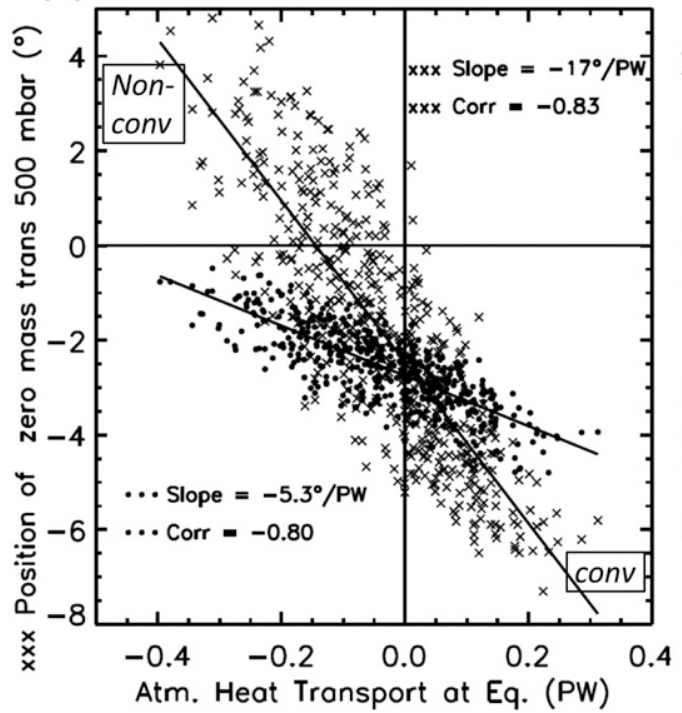

(b)

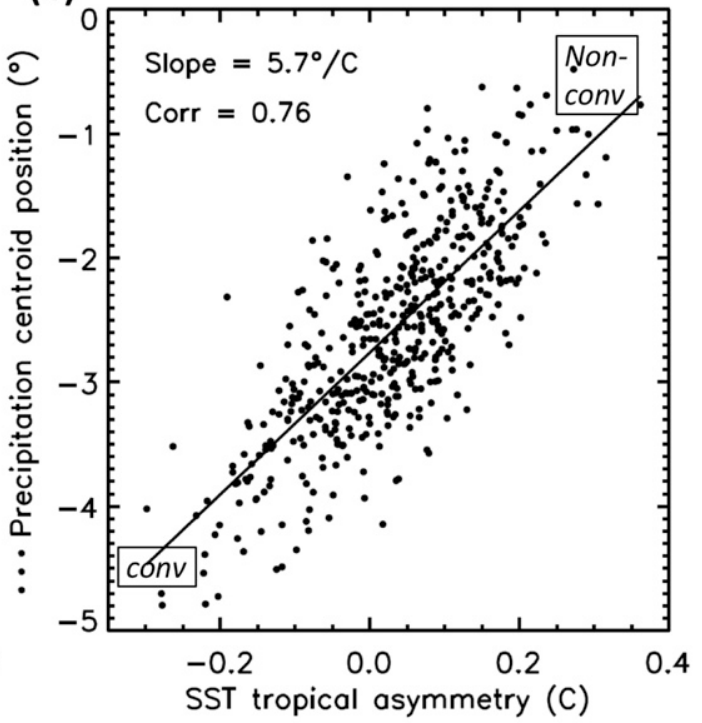

FIG. 9. (a) Scatterplot of the ITCZ location as measured by 1) the precipitation centroid latitude (circles) or 2) the position of the ascending branch of the tropical Hadley cell-zero mass transport at 500 mbar (crosses) vs the crossequatorial northward atmospheric heat transport $\left(T_{\mathrm{Eq}}^{A}\right)$. (b) Scatterplot of the precipitation centroid latitude vs the SST tropical asymmetry, defined as averaged SST from the equator to $20^{\circ} \mathrm{N}$ minus SST from the equator to $20^{\circ} \mathrm{S}$. Each dot represents one annual mean; 500 years of the control simulation are represented. High/positive (low/negative) $T_{\mathrm{Eq}}^{A}$ values represent convective (nonconvective) decades. The regression slope and correlation coefficient are labeled in each figure.

$(\sim 0.03 \mathrm{PW})$, as reflected in Fig. $8 \mathrm{f}$. The former win such that 12 years after the convective peak, the net northward atmospheric heat transport at the equator (the sum of these four terms) is slightly northward (Figs. 7 and $8 \mathrm{e})$. Note that the patterns of longwave atmospheric heating are dominated by changes in OLR, with the exception of the region above the Weddell Sea where the atmosphere gains heat due to extra LW released from the ocean (cf. Figs. S2i, S2b, S2e). Increased evaporation and sensible fluxes enhance the atmospheric convergence of heat above the Weddell Sea convective zone, but the overall patterns are rather complicated and patchy across the rest of the Southern Hemisphere, resulting from secondary changes in winds, etc. (Figs. S3f,g).

Interestingly, the convection-driven change in $\mathrm{SH}$ condensational heating (Fig. 8f) is much larger than the change in evaporative fluxes, reaching a peak of $\sim 0.21 \mathrm{PW}$ about 10 years after the peak in ocean convection. Since precipitation converts latent to sensible heat, it does not affect the total energy budget of the atmosphere. However, this implies that during convective decades there is an increased flux of latent energy in the $\mathrm{SH}$ atmosphere associated with increased moisture, which is then converted into sensible heat and exported to the $\mathrm{NH}$ as previously discussed. Below, we discuss how these convectiondriven changes in atmospheric heat transport are linked to the position of the ITCZ.

\section{d. Implications for SH subtropics and tropics: Shifts in the ITCZ}

The ITCZ is the surface expression of the ascending branch of the Hadley cell and represents the maximum in tropical precipitation. Here we define the position of the ITCZ as the median latitude of the zonally integrated precipitation from $20^{\circ} \mathrm{S}$ to $20^{\circ} \mathrm{N}$ [as in Frierson and Hwang (2012)]. Because of the double-ITCZ bias (see section 2 and Fig. 1a), the precipitation centroid is always anomalously located in the SH in our simulation (Fig. 9). We also use the position of the ascending branch of the Hadley cell to represent the ITCZ. This is calculated as the position of the zero mass atmospheric transport at 500 mbar [as in Hwang and Frierson (2013)]; its location shifts between $\sim 7^{\circ} \mathrm{S}$ and $5^{\circ} \mathrm{N}$ as the system oscillates between strongly convective and nonconvective decades (Fig. 9).

In the tropics, the thermally direct Hadley cell governs the atmospheric transport of energy via its upper branch and the transport of moisture via its lower cell. Assuming that the ratio of energy to moisture transport stays constant, any changes in the cross-equatorial energy 
transport should be anticorrelated with the tropical precipitation shift. This concept was the basis of the theoretical frameworks for interpreting changes in ITCZ location in response to extratropical forcing (Kang et al. 2008, 2009) and follow-up work (e.g., Frierson and Hwang 2012). This is exactly what we find here too.

During convective decades, a gain of energy in the high-latitude $\mathrm{SH}$ atmosphere means that less atmospheric heat is transported from the equator to the $\mathrm{SH}$ extratropics via the southern Hadley cell in the tropics and via eddies in southern midlatitudes. In the southern tropics, this implies a weakening of the SH Hadley cell (Fig. 4b). Furthermore, anomalously northward heat transport from the SH into the NH (Fig. 8e) implies an anomalously stronger NH Hadley cell during convective decades (Fig. 4b), and an anomalous southward transport of moisture (Figs. 7 and 8e). At the equator, the intensified southward water vapor (latent) heat transport during convective decades (Fig. 8e) brings more water vapor and precipitation to the SH (Figs. 1c,d), producing an interhemispheric asymmetry in atmospheric humidity, shifting southward the centroid of precipitation (Fig. 9a) and increasing the southern band of tropical high convective clouds (Fig. 6e). In agreement with other studies [e.g., the review by Schneider et al. (2014)], the ITCZ shifts toward the anomalously warmer hemisphere, which is the SH during convective decades, consistent with a decreased hemispheric asymmetry in tropical temperatures (Fig. 9b). Moreover, associated with the changes in the tropical cells, we observe a weakening (strengthening) of the southern (northern) trade winds (Fig. 5b) during convective decades.

In summary, across the 500 years of the control simulation of the CM2Mc model, we see clear correlations between ITCZ displacement and the strength of convective events (Figs. 9a,b): the stronger the SO convective event, the stronger the anomalous northward heat transport at the equator (with a 10-yr lag; Fig. 8e) and the larger the southward ITCZ shifts. Interestingly, the expected interannual latitudinal shift of the precipitation centroid as a function of cross-equatorial atmospheric heat transport is more sensitive in our model $\left(-5.3^{\circ} \mathrm{PW}^{-1}\right)$ than observed so far from 1979 to $2009\left(-1.6 \pm 0.7^{\circ} \mathrm{PW}^{-1}\right)$ or modeled $\left(-3^{\circ} \mathrm{PW}^{-1}\right)$ with the GFDL CM2.1 (Donohoe et al. 2014). Previously, Donohoe et al. (2013) found similar relationships [statistically indistinguishable from those in Donohoe et al. (2014)] on seasonal time scales and in the annual-mean response due to external climate forcing. A qualitatively similar negative correlation between atmospheric transport and ITCZ position is found across CMIP5 models (Hwang and Frierson 2013).

\section{Summary}

The present study provides new evidence for a global atmospheric teleconnection mechanism associated with recurrent natural variability in SO open-sea convection that has only been previously studied in Kiel model simulations (e.g., Latif et al. 2013). In the CM2Mc model, intrinsic multidecadal variability in Weddell Sea openocean convection develops into variability in Southern Ocean SSTs that affects the global atmospheric and oceanic circulation, and results in a global energy balance redistribution between the Northern and Southern Hemispheres. Analyzing the global energy flux has proven to be a particularly useful diagnostic in interpreting the global response to high-latitude SO thermal forcing. The schematic in Fig. 7 summarizes the teleconnections associated to convective decades in the CM2Mc model, and our main findings are summarized below.

During convective decades:

1) Heat is released from the ocean subsurface to the atmosphere, which results in oceanic surface warming in the entire Southern Hemisphere, and subsurface cooling.

2) The atmosphere warms almost everywhere, more so in the Southern Ocean and more in the SH than in the NH.

3) The southern Ferrel cell weakens due to a decrease in the $30^{\circ}-60^{\circ} \mathrm{S}$ meridional gradient of SSTs. This weakening is associated with changes in the surface pressure pattern such that SO westerly winds and the SAM weaken, in agreement with reduced midlatitude baroclinicity.

4) The TOA incoming radiation increases in the SH. This TOA anomaly is transported from the $\mathrm{SH}$ to the $\mathrm{NH}$ through the atmosphere and results in a maximum increase in the $\mathrm{NH}$ outgoing radiation approximately 12 years later. The northward ocean heat transport increases at the equator but this anomalous heat is all stored in the $\mathrm{NH}$ oceans without affecting the $\mathrm{NH}$ atmospheric budget.

5) The northward dry static energy transport increases at the equator, and this is partially compensated by an increase in latent heat transport that is more southward during these decades.

6) Changes in cross-equatorial energy budget in the atmosphere-anomalous northward heat transportresult in a southward shift of the ITCZ and clouds, increased water vapor in the $\mathrm{SH}$, and weakening (strengthening) of the southern (northern) trade winds and Hadley cells. 
In summary, we see that global energetic equilibrium is coupled to the response to Weddell Sea convection. The increased TOA radiative flux into the system at $\mathrm{SH}$ ice latitudes is transmitted into the $\mathrm{SH}$ tropics, then across the equator and into the Northern Hemisphere via the altered Hadley circulation. The Hadley circulation thus transports anomalous energy into the cooler (northern) hemisphere via its upper branch and moisture into the opposite (southern) hemisphere, such that the ITCZ shifts to the warmer (southern) hemisphere.

\section{Discussion}

\section{a. Comparison with previous studies}

Our suggested atmospheric teleconnections agree qualitatively well with results derived from the study of composites of convective and nonconvective phases in the Kiel model (Latif et al. 2013), despite large differences in the frequency and intensity of convective events between the two models. As in this study, they showed a warming of the Southern Ocean associated with convective periods, as well as a decrease in sea ice coverage and a weakening of SO westerly winds. Previously, Ma and $\mathrm{Wu}$ (2011) found similar one-time teleconnections in an experiment that dumped freshwater over the Antarctic Ocean [in the Fast Ocean Atmosphere Model (FOAM)], which inhibits deep convection and hence effectively mimics the teleconnections created by a nonconvective event. Latif et al. (2013) also noticed that the tropical rain belt (ITCZ) shifts southward during convective phases in the Atlantic, as we find here too. The tight correlations we find between the crossequatorial atmospheric heat transport and ITCZ location are in good agreement with proposed theories and recent findings from the atmospheric literature (e.g., Frierson et al. 2013; Kang et al. 2015; Donohoe et al. 2014; Schneider et al. 2014). As in Donohoe et al. (2014), we find that the interannual anomalies in crossequatorial atmospheric transport are not affected by anomalies in the oceanic heat transport. However, unlike Donohoe et al. (2014), who found cross-equatorial heat transport anomalies to be dominated by atmospheric radiative processes at the TOA and of tropical origin, here we discuss and quantify anomalies of extratropical origin (section $3 \mathrm{c}$ ).

We have found that the Hadley circulation and ITCZ response to a southern extratropical perturbation is driven by the thermal contrast between the hemispheres and the need to transport heat out of the warmed hemisphere and into the cooled hemisphere, as previously found in a slab-ocean setting (e.g., Chiang and Bitz 2005; Kang et al. 2008; Frierson and Hwang 2012).
However, at least two recent studies suggest that perturbations of southern extratropical origin do not significantly impact the patterns of tropical precipitation in fully coupled models as shown by Kay et al. (2016) in the CESM1 model and by Hawcroft et al. (2016) in the HadGEM2-ES model. Moreover, Deser and Sun (2015) and Tomas et al. (2016) showed a weak equatorially symmetric atmospheric response to perturbations of Arctic origin in the fully coupled CCSM4 model (same model family as CESM1). These authors suggested that if ocean dynamics is allowed to respond to the imposed thermal perturbation, most of the cross-equatorial heat transport changes occur in the ocean rather than in the atmosphere, which mitigates the need for a strong ITCZ shift.

How can we reconcile these studies with our own work here? Our results suggest that tropical responses to highlatitude radiative changes depend on the partitioning between the atmospheric and ocean components of the cross-equatorial energy transport, which is highly model dependent. Whereas in the HadGEM and CESM models most of the cross-equatorial heat transport changes occurred in the ocean, in our GFDL-CM2Mc model the cross-equatorial heat transport perturbation is accomplished equally by the atmosphere and ocean (Fig. 7).

Atmospheric meridional heat transport (and hence the cross-equatorial energy transport) depends to a large degree on the radiative cloud feedback strength (Zelinka and Hartmann 2012; Huang and Zhang 2014). Bischoff and Schneider $(2014,2016)$ showed via theory and simulations that the atmospheric net energy input (NEI) near the equator controls the sensitivity of the ITCZ position to cross-equatorial energy transport. This suggests that a different representation of tropical processes that change the NEI (e.g., changes in cloud or aerosol distribution, energy uptake by the equatorial oceans, El Niño) across different climate models can on its own lead to different ITCZ shifts. To complicate matters further, various climate feedbacks interact with each other (e.g., Feldl et al. 2017). Additionally, the ocean provides a dynamic boundary condition for atmospheric dynamics, such that atmospheric feedback processes depend on the background ocean state (e.g., Winton 2003; van der Swaluw et al. 2007; Zhang et al. 2010; Rose et al. 2014; Yang et al. 2014; Trossman et al. 2016).

Mechoso et al. (2016) suggested that the strength of the ITCZ shift in response to a SO heat perturbation depends on the strength of the coupling between stratocumulus clouds and SST in the eastern tropical Pacific and Atlantic. They found that the direction of the ITCZ shift was consistent with our results but the strength was different in the two models analyzed (UCLA CGCM 
and NorESM). In our CM2Mc model, we find that low cloud coverage is anticorrelated with SSTs over most of the globe on interannual time scales with the strongest signals seen in stratocumulus regions, suggesting a positive low cloud-SST feedback. Seviour et al. $(2016,2017)$ found that a positive low cloud-SST feedback in the high-latitude SO reinforces an initial SO cooling perturbation when analyzing the response of the SO to a step increase in the ozone in the CM2Mc model. However, Ferreira et al. (2015) find the opposite behavior when the same experiment is carried out in the NCAR CCSM3.5 model, a lineal ancestor of the model used in Kay et al. (2016); there a negative cloud-SST feedback dampens an initial SO cooling perturbation. Hence, a strong cloud-SST feedback could potentially explain the strong atmospheric response to SO radiative perturbation in our model runs, compared to those in Kay et al. (2016) and Hawcroft et al. (2016).

\section{b. Potential mechanisms for regularity}

In our model, the convective events are multidecadal and very regular when compared to the other CMIP5 Earth system simulations (de Lavergne et al. 2014). This regularity facilitates the analysis of global teleconnections in the current paper, as each convective event is self-similar to the other ones. However, such regularity suggests that the variability associated with convective events might feedback too strongly into the onset of posterior convective events. According to Galbraith et al. (2011), it is the westward surface advection of anomalous salty water that helps with the onset of convection, and the westward advection of freshwater that shuts down convection later on. We hypothesize that the convection-driven atmospheric variability discussed in this paper is responsible for the propagation of salty and freshwater anomalies necessary to start and stop SO convection. The mechanisms and ocean-atmosphere feedbacks driving the high periodicity seen in our model will be explored in a separate future paper. Another possible feedback in our model results might be related to the intensification of $\mathrm{SH}$ westerlies during nonconvective decades (section $3 b$ ). This might trigger an anomalous intensification in the AMOC southward transport as seen in non-eddyresolving models [for a review of the topic, see Gent (2016)], which could bring heat anomalies into the Weddell Sea convective zone, helping to shift the system into the convective regime [mechanism discussed also in Martin et al. (2013) for the Kiel model]. Oceanic teleconnections will be studied in detail in a followup paper.

The GFDL models sit within a class of CMIP5 models that have a base state with active convection in the SO and that are in general warm, compared to other models such as the CESM-BGC, which has no SO convection and colder SO SSTs (de Lavergne et al. 2014). The GFDL model we use here (CM2Mc), in particular, has a very warm summertime Southern Ocean and is biased toward a double ITCZ (Fig. 1a). We hypothesize that a possible cause or consequence for an anomalously warm Southern Ocean in our model (and maybe in other models) is the state of active convection. This study hence contributes to understanding the biases that might arise when warm and convective models are used to describe teleconnections and natural variability. A strong SO mode present in convective models such as ours facilitates the understanding of teleconnections that originate in the $\mathrm{SO}$ in isolation from those of tropical origin (A. Gnanadesikan and M. Pradal 2017, unpublished manuscript).

\section{c. Implication for past and future climates}

This study also has implications for our understanding of past climates. Even though open-ocean convection is not the main mechanism to form deep waters today, the AABW might have been predominantly formed via open-ocean convection during the last glacial maximum (e.g., Gordon 2014). Based on analysis of the recurring multicentennial convective events in the Kiel climate model, Pedro et al. (2016) suggest that convective events could have contributed to drive or amplify Antarctic warming events as observed in the paleoclimate record from ice cores, although events such as DansgaardOeschger are of millennial scale. Importantly, the time lag between convective events, here on the order of decades, is very different across the latest generation of climate models (de Lavergne et al. 2014; Pedro et al. 2016). For example, in the Kiel model the thickness and compactness of newly formed ice were shown to define the intensity of the deep convection and multicentennial frequency of occurrence, with deep convection less frequent under thicker sea ice (Martin et al. 2013). Even if open-ocean convection is no longer the principal mechanism for SO deep water formation, it is crucial to study the remarkable climate variability associated with SO open ocean convection, as this process is simulated in most Earth system models and thus could present a challenge (or bias) to understanding true, observed climate variability and future climate-driven trends.

In recent decades, increased freshening and warming of the SO surface water have been observed (e.g., Gille 2002; Gille 2008; Helm et al. 2010; Durack et al. 2012) and are predicted under future climate scenarios (e.g., Meehl et al. 2007). This increased stratification will decrease the probability of SO open ocean convective events as seen across CMIP5 models (de Lavergne et al. 
2014). Indeed, a polynya as large as the one in the 1970 s has never been observed again despite continuous satellite monitoring, which could reflect a decrease in vertical mixing due to climate change. As already hypothesized by Latif et al. (2013), some of the observed variations in climate of recent decades might have a contribution (or attenuation) of convective origin. The observed strengthening of SAM and SO westerlies (Thompson and Solomon 2002), deep sea warming (Purkey and Johnson 2010), and decrease in the rate of SO deep-water production (Purkey and Johnson 2013) over the past 30-40 years all agree-at least in the direction of change-with a hypothetical decrease or stoppage of SO convection. Most recently, Zanowski et al. (2015) estimated using the GFDL-ESM2G model that the closing of the Weddell Sea polynya of the 1970s might have contributed $10 \%( \pm 8 \%)$ to the observed abyssal warming since then. On the other hand, a stoppage in convection would prevent subsurface heat from reaching the SO surface and atmosphere, temporarily attenuating the predicted raise in global atmospheric temperatures throughout the twenty-first century. We suggest that future research should focus on estimating the contribution that an eventual shutdown in SO convection would have on the atmosphere of a warming planet, perhaps along the lines of Drijfhout (2015), who has estimated the hiatus effect of an eventual collapse of the AMOC in the North Atlantic.

Emerging work-mostly focused on the Northern Hemisphere signal propagation-has used data and climate models to show how the extratropics can be efficient in shifting the ITCZ, with imposed cooling (warming) in the northern extratropics resulting in a southward (northward) shift of the ITCZ. The ITCZ position generally depends on the interhemispheric temperature gradient and moves toward the warmer hemisphere on different time scales ranging from seasonal scales to much larger time scales as estimated in paleoclimate data going back to the last ice age [e.g., during the Holocene or during Dansgaard-Oeschger millennial cycles; see review by Schneider et al. (2014)]. In recent decades, a large increase in anthropogenic aerosol emissions mainly from the industrialized $\mathrm{NH}$ has contributed to the differential cooling of the northern extratropics in the mid to late-twentieth century (Tett et al. 2002), with a zonal-mean ITCZ southward migration (Rotstayn and Lohmann 2002; Hwang et al. 2013). Conversely, twenty-first-century reductions in aerosol emissions and a continuous increase of greenhouse gases should warm the Northern Hemisphere and act to shift the ITCZ northward (Allen et al. 2015; Byrne and O'Gorman 2013). Our work suggests that future projections of ITCZ shifts will need to take into account the influence of extratropical SO perturbations. Further research is needed to understand the strength of such teleconnections across climate models, as they appear to depend on the feedback strength between clouds, SST, and atmospheric circulation both in the tropics (e.g., Mechoso et al. 2016) and in the extratropics (e.g., Seviour et al. 2016, 2017).

We have shown that in the CM2Mc model the Hadley circulation and the ITCZ are sensitive to changes in the SO SSTs and Weddell Sea ice cover and convective status, parameters that have changed significantly in the past and will continue to change in a future warmer world. In turn, ITCZ migrations can change the hydroclimate drastically in certain tropical areas such as the African Sahel (e.g., Broecker and Putnam 2013), with huge and very concrete implications for the local economies and livelihoods of people living in these areas.

Acknowledgments. We thank Dr. Raffa Bernardello for contributing the long simulation needed in this paper and for discussions on Southern Ocean dynamics. A.C. is grateful for the "Beatriu de Pinos" fellowship with support from the Secretariat of Universities and Research of the Ministry of Economy and Knowledge of the Government of Catalonia and the program Marie Curie Actions COFUND of the 7th Framework Program for Research and Technological Development of the European Union. I.M. is grateful for support from a University Research Foundation and Bridge Funding grants at University of Pennsylvania. A.G. thanks the National Science Foundation for support under Grants FESD-1338814 and OCE-1536554.

\section{REFERENCES}

Allen, R. J., A. T. Evan, and B. B. B. Booth, 2015: Interhemispheric aerosol radiative forcing and tropical precipitation shifts during the late twentieth century. J. Climate, 28, 8219-8246, doi:10.1175/JCLI-D-15-0148.1.

Bernardello, R., I. Marinov, J. B. Palter, E. D. Galbraith, and J. L. Sarmiento, 2014a: Impact of Weddell Sea deep convection on natural and anthropogenic carbon in a climate model. Geophys. Res. Lett., 41, 7262-7269, doi:10.1002/2014GL061313.

,,--- J. L. Sarmiento, E. D. Galbraith, and R. D. Slater, 2014b: Response of the ocean natural carbon storage to projected twenty-first-century climate change. J. Climate, 27, 2033-2053, doi:10.1175/JCLI-D-13-00343.1.

Bischoff, T., and T. Schneider, 2014: Energetic constraints on the position of the intertropical convergence zone. J. Climate, 27, 4937-4951, doi:10.1175/JCLI-D-13-00650.1.

$\longrightarrow$, and - 2016: The equatorial energy balance, ITCZ position, and double-ITCZ bifurcations. J. Climate, 29, 2997-3013, doi:10.1175/JCLI-D-15-0328.1.

Broccoli, A. J., and S. A. Klein, 2010: Comment on "Observational and model evidence for positive low-level cloud feedback." Science, 329, 277, doi:10.1126/science.1186796. 
— K. A. Dahl, and R. J. Stouffer, 2006: Response of the ITCZ to Northern Hemisphere cooling. Geophys. Res. Lett., 33, L01702, doi:10.1029/2005GL024546.

Broecker, W. S., and A. E. Putnam, 2013: Hydrologic impacts of past shifts of Earth's thermal equator offer insight into those to be produced by fossil fuel $\mathrm{CO}_{2}$. Proc. Natl. Acad. Sci. USA, 110, 16 710-16 715, doi:10.1073/pnas.1301855110.

Byrne, M. P., and P. A. O'Gorman, 2013: Link between land-ocean warming contrast and surface relative humidities in simulations with coupled climate models. Geophys. Res. Lett., 40, 5223-5227, doi:10.1002/grl.50971.

Cheng, W., C. M. Bitz, and J. C. H. Chiang, 2007: Adjustment of the global climate to an abrupt slowdown of the Atlantic meridional overturning circulation: Mechanisms and impacts. Ocean Circulation: Mechanisms and Impacts-Past and Future Changes of Meridional Overturning, Geophys. Monogr., Vol. 173, Amer. Geophys. Union, 295-314.

Chiang, J. C., and C. M. Bitz, 2005: Influence of high latitude ice cover on the marine intertropical convergence zone. Climate Dyn., 25, 477-496, doi:10.1007/s00382-005-0040-5.

, and A. R. Friedman, 2012: Extratropical cooling, interhemispheric thermal gradients, and tropical climate change. Annu. Rev. Earth Planet. Sci., 40, 383-412, doi:10.1146/ annurev-earth-042711-105545.

_ M. Biasutti, and D. S. Battisti, 2003: Sensitivity of the Atlantic intertropical convergence zone to Last Glacial Maximum boundary conditions. Paleoceanography, 18, 1094, doi:10.1029/ 2003PA000916.

— W. Cheng, and C. M. Bitz, 2008: Fast teleconnections to the tropical Atlantic sector from Atlantic thermohaline adjustment. Geophys. Res. Lett., 35, L07704, doi:10.1029/2008GL033292.

Clement, A. C., R. Burgman, and J. R. Norris, 2009: Observational and model evidence for positive low-level cloud feedback. Science, 325, 460-464, doi:10.1126/science.1171255.

,$- \ldots$, and — 2010: Response to Comment on "Observational and model evidence for positive low-level cloud feedback." Science, 329, 277, doi:10.1126/science.1187667.

Cook, E. R., B. M. Buckley, R. D. D'Arrigo, and M. J. Peterson, 2000: Warm-season temperatures since $1600 \mathrm{BC}$ reconstructed from Tasmanian tree rings and their relationship to large-scale sea surface temperature anomalies. Climate Dyn., 16, 79-91, doi:10.1007/s003820050006.

de Lavergne, C., J. B. Palter, E. D. Galbraith, R. Bernardello, and I. Marinov, 2014: Cessation of deep convection in the open Southern Ocean under anthropogenic climate change. Nat. Climate Change, 4, 278-282, doi:10.1038/nclimate2132.

Delworth, T. L., and Coauthors, 2006: GFDL's CM2 global coupled climate models. Part I: Formulation and simulation characteristics. J. Climate, 19, 643-674, doi:10.1175/ JCLI3629.1.

Deser, C., and L. Sun, 2015: The role of ocean-atmosphere coupling in the zonal-mean atmospheric response to Arctic sea ice loss. J. Climate, 28, 2168-2186, doi:10.1175/ JCLI-D-14-00325.1.

Dethleff, D., 1994: Polynyas as a possible source for enigmatic island atmospheric plumes. The Polar Oceans and Their Role in Shaping the Global Environment, Geophys. Monogr., Vol. 85, Amer. Geophys. Union, 475-483.

Donohoe, A., J. Marshall, D. Ferreira, and D. McGee, 2013: The relationship between ITCZ location and cross-equatorial atmospheric heat transport: From the seasonal cycle to the Last Glacial Maximum. J. Climate, 26, 3597-3618, doi:10.1175/ JCLI-D-12-00467.1.
,,,--- K. Armour, and D. McGee, 2014: The interannual variability of tropical precipitation and interhemispheric energy transport. J. Climate, 27, 3377-3392, doi:10.1175/ JCLI-D-13-00499.1.

Drijfhout, S., 2015: Competition between global warming and an abrupt collapse of the AMOC in Earth's energy imbalance. Sci. Rep., 5, 14877, doi:10.1038/srep14877.

Dunne, J. P., and Coauthors, 2012: GFDL's ESM2 global coupled climate-carbon Earth system models. Part I: Physical formulation and baseline simulation characteristics. J. Climate, 25 , 6646-6665, doi:10.1175/JCLI-D-11-00560.1.

Durack, P. J., S. E. Wijffels, and R. J. Matear, 2012: Ocean salinities reveal strong global water cycle intensification during 1950 to 2000. Science, 336, 455-458, doi:10.1126/ science. 1212222 .

Feldl, N., S. Bordoni, and T. M. Merlis, 2017: Coupled highlatitude climate feedbacks and their impact on atmospheric heat transport. J. Climate, 30, 189-201, doi:10.1175/ JCLI-D-16-0324.1.

Ferreira, D., J. Marshall, C. M. Bitz, S. Solomon, and A. Plumb, 2015: Antarctic Ocean and sea ice response to ozone depletion: A two-time-scale problem. J. Climate, 28, 1206-1226, doi:10.1175/JCLI-D-14-00313.1.

Frierson, D. M. W., and Y.-T. Hwang, 2012: Extratropical influence on ITCZ shifts in slab ocean simulations of global warming. J. Climate, 25, 720-733, doi:10.1175/ JCLI-D-11-00116.1.

__ , and Coauthors, 2013: Contribution of ocean overturning circulation to tropical rainfall peak in the Northern Hemisphere. Nat. Geosci., 6, 940-944, doi:10.1038/ ngeo1987.

Galbraith, E. D., and Coauthors, 2011: Climate variability and radiocarbon in the $\mathrm{CM} 2 \mathrm{Mc}$ Earth system model. J. Climate, 24, 4230-4254, doi:10.1175/2011JCLI3919.1.

Gallée, H., 1997: Air-sea interactions over Terra Nova Bay during winter: Simulation with a coupled atmosphere-polynya model. J. Geophys. Res., 102, 13835-13849, doi:10.1029/ 96JD03098.

Gent, P. R., 2016: Effects of Southern Hemisphere wind changes on the meridional overturning circulation in ocean models. Annu. Rev. Mar. Sci., 8, 79-94, doi:10.1146/ annurev-marine-122414-033929.

Gille, S. T., 2002: Warming of the Southern Ocean since the 1950s. Science, 295, 1275-1277, doi:10.1126/science.1065863.

_ 2008: Decadal-scale temperature trends in the Southern Hemisphere ocean. J. Climate, 21, 4749-4765, doi:10.1175/ 2008JCLI2131.1.

Gordon, A. L., 1978: Deep Antarctic convection west of Maud Rise. J. Phys. Oceanogr., 8, 600-612, doi:10.1175/ 1520-0485(1978)008<0600:DACWOM > 2.0.CO;2.

_ 1982: Weddell Deep Water variability. J. Mar. Res., 40, 199_ 217.

- 1991: Two stable modes of Southern Ocean winter stratification. Deep Convection and Deep Water Formation in the Oceans, Elsevier Oceanography Series, Vol. 57, 17-35, doi:10.1016/S0422-9894(08)70058-8.

_ 2014: Oceanography: Southern Ocean polynya. Nat. Climate Change, 4, 249-250, doi:10.1038/nclimate2179.

Hawcroft, M., J. M. Haywood, M. Collins, A. Jones, A. C. Jones, and G. Stephens, 2016: Southern Ocean albedo, inter-hemispheric energy transports and the double ITCZ: Global impacts of biases in a coupled model. Climate Dyn., 48, 2279-2295, doi:10.1007/ s00382-016-3205-5. 
Helm, K. P., N. L. Bindoff, and J. A. Church, 2010: Changes in the global hydrological-cycle inferred from ocean salinity. Geophys. Res. Lett., 37, L18701, doi:10.1029/2010GL044222.

Heuze, C., K. J. Heywood, D. P. Stevens, and J. K. Ridley, 2013: Southern Ocean bottom water characteristics in CMIP5 models. Geophys. Res. Lett., 40, 1409-1414, doi:10.1002/ grl.50287.

Huang, Y., and M. Zhang, 2014: The implication of radiative forcing and feedback for meridional energy transport. Geophys. Res. Lett., 41, 1665-1672, doi:10.1002/2013GL059079.

Hwang, Y.-T., and D. M. W. Frierson, 2013: Link between the double-Intertropical Convergence Zone problem and cloud biases over the Southern Ocean. Proc. Natl. Acad. Sci. USA, 110, 4935-4940, doi:10.1073/pnas.1213302110.

— _ _ - and S. M. Kang, 2013: Anthropogenic sulfate aerosol and the southward shift of tropical precipitation in the late 20th century. Geophys. Res. Lett., 40, 2845-2850, doi:10.1002/ grl.50502.

Kang, S. M., I. M. Held, D. M. W. Frierson, and M. Zhao, 2008: The response of the ITCZ to extratropical thermal forcing: Idealized slab-ocean experiments with a GCM. J. Climate, 21, 35213532, doi:10.1175/2007JCLI2146.1.

- D. M. W. Frierson, and I. M. Held, 2009: The tropical response to extratropical thermal forcing in an idealized GCM: The importance of radiative feedbacks and convective parameterization. J. Atmos. Sci., 66, 2812-2827, doi:10.1175/2009JAS2924.1.

—, L. M. Polvani, J. C. Fyfe, and M. Sigmond, 2011: Impact of polar ozone depletion on subtropical precipitation. Science, 332, 951-954, doi:10.1126/science.1202131.

_ I. M. Held, and S. P. Xie, 2014: Contrasting the tropical responses to zonally asymmetric extratropical and tropical thermal forcing. Climate Dyn., 42, 2033-2043, doi:10.1007/ s00382-013-1863-0.

—, R. Seager, and D. M. W. Frierson, 2015: Croll revisited: Why is the Northern Hemisphere warmer than the Southern Hemisphere? Climate Dyn., 44, 1457-1472, doi:10.1007/ s00382-014-2147-z.

Kay, J. E., C. Wall, V. Yettella, B. Medeiros, C. Hannay, P. Caldwell, and C. Bitz, 2016: Global climate impacts of fixing the Southern Ocean shortwave radiation bias in the Community Earth System Model (CESM). J. Climate, 29, 4617-4636, doi:10.1175/JCLI-D-15-0358.1.

Latif, M., T. Martin, and W. Park, 2013: Southern Ocean sector centennial climate variability and recent decadal trends. J. Climate, 26, 7767-7782, doi:10.1175/JCLI-D-12-00281.1.

Le Quesne, C., C. Acuna, J. A. Boninsegna, A. Rivera, and J. Barichivich, 2009: Long-term glacier variations in the Central Andes of Argentina and Chile, inferred from historical records and tree-ring reconstructed precipitation. Palaeogeogr. Palaeoclimatol. Palaeoecol., 281, 334-344, doi:10.1016/j.palaeo.2008.01.039.

Li, G., and S. P. Xie, 2014: Tropical biases in CMIP5 multimodel ensemble: The excessive equatorial Pacific cold tongue and double ITCZ problems. J. Climate, 27, 1765-1780, doi:10.1175/ JCLI-D-13-00337.1.

Limpasuvan, V., and D. L. Hartmann, 2000: Wave-maintained annular modes of climate variability. J. Climate, 13, 4414-4429, doi:10.1175/1520-0442(2000)013<4414:WMAMOC >2.0.CO;2.

Ma, H., and L. Wu, 2011: Global teleconnections in response to freshening over the Antarctic Ocean. J. Climate, 24, 10711088, doi:10.1175/2010JCLI3634.1.

Mahajan, S., R. Saravanan, and P. Chang, 2011: The role of the wind-evaporation-sea surface temperature (WES) feedback as a thermodynamic pathway for the equatorward propagation of high-latitude sea ice-induced cold anomalies. J. Climate, 24, 1350-1361, doi:10.1175/2010JCLI3455.1.

Marshall, J., A. Donohoe, D. Ferreira, and D. McGee, 2014: The ocean's role in setting the mean position of the Inter-Tropical Convergence Zone. Climate Dyn., 42, 1967-1979, doi:10.1007/ s00382-013-1767-z.

Martin, T., W. Park, and M. Latif, 2013: Multi-centennial variability controlled by Southern Ocean convection in the Kiel Climate Model. Climate Dyn., 40, 2005-2022, doi:10.1007/ s00382-012-1586-7.

- — - and - 2015: Southern Ocean forcing of the North Atlantic at multi-centennial time scales in the Kiel Climate Model. Deep-Sea Res. II, 114, 39-48, doi:10.1016/ j.dsr2.2014.01.018.

Martinson, D. G., P. D. Killworth, and A. L. Gordon, 1981: A convective model for the Weddell polynya. J. Phys. Oceanogr., 11, 466-488, doi:10.1175/1520-0485(1981)011<0466: ACMFTW $>2.0$.CO;2.

Mechoso, C. R., and Coauthors, 2016: Can reducing the incoming energy flux over the Southern Ocean in a CGCM improve its simulation of tropical climate? Geophys. Res. Lett., 43, $11057-$ 11 063, doi:10.1002/2016GL071150.

Meehl, G. A., and Coauthors, 2007: The WCRP CMIP3 multimodel dataset: A new era in climate change research. Bull. Amer. Meteor. Soc., 88, 1383-1394, doi:10.1175/BAMS-88-9-1383.

Park, W., and M. Latif, 2008: Multidecadal and multicentennial variability of the meridional overturning circulation. Geophys. Res. Lett., 35, L22703, doi:10.1029/2008GL035779.

Pedro, J. B., T. Martin, E. J. Steig, M. Jochum, W. Park, and S. O. Rasmussen, 2016: Southern Ocean deep convection as a driver of Antarctic warming events. Geophys. Res. Lett., 43, 2192 2199, doi:10.1002/2016GL067861.

Peterson, R. G., and W. B. White, 1998: Slow oceanic teleconnections linking the Antarctic Circumpolar Wave with the tropical El Niño-Southern Oscillation. J. Geophys. Res., 103, 24 573-24 583, doi:10.1029/98JC01947.

Purkey, S. G., and G. C. Johnson, 2010: Warming of global abyssal and deep Southern Ocean waters between the 1990s and 2000s: Contributions to global heat and sea level rise budgets. J. Climate, 23, 6336-6351, doi:10.1175/2010JCLI3682.1.

—, and —, 2013: Antarctic Bottom Water warming and freshening: Contributions to sea level rise, ocean freshwater budgets, and global heat gain. J. Climate, 26, 6105-6122, doi:10.1175/JCLI-D-12-00834.1.

Rose, B. E. J., K. C. Armour, D. S. Battisti, N. Feldl, and D. D. B. Koll, 2014: The dependence of transient climate sensitivity and radiative feedbacks on the spatial pattern of ocean heat uptake. Geophys. Res. Lett., 41, 1071-1078, doi:10.1002/ 2013 GL058955.

Rotstayn, L. D., and U. Lohmann, 2002: Tropical rainfall trends and the indirect aerosol effect. J. Climate, 15, 2103-2116, doi:10.1175/1520-0442(2002)015<2103: TRTATI>2.0.CO;2.

Sallée, J. B., E. Shuckburgh, N. Bruneau, A. J. S. Meijers, T. J. Bracegirdle, Z. Wang, and T. Roy, 2013: Assessment of Southern Ocean water mass circulation and characteristics in CMIP5 models: Historical bias and forcing response. J. Geophys. Res. Oceans, 118, 1830-1844, doi:10.1002/ jgrc.20135.

Schneider, T., T. Bischoff, and G. H. Haug, 2014: Migrations and dynamics of the intertropical convergence zone. Nature, 513, 45-53, doi:10.1038/nature13636. 
Seviour, W. J. M., A. Gnanadesikan, and D. W. Waugh, 2016: The transient response of the Southern Ocean to stratospheric ozone depletion. J. Climate, 29, 7383-7396, doi:10.1175/ JCLI-D-16-0198.1.

,,--- , and M. A. Pradal, 2017: Transient response of the Southern Ocean to changing ozone: Regional responses and physical mechanisms. J. Climate, 30, 2463-2480, doi:10.1175/ JCLI-D-16-0474.1.

Shevenell, A. E., A. E. Ingalls, E. W. Domack, and C. Kelly, 2011: Holocene Southern Ocean surface temperature variability west of the Antarctic Peninsula. Nature, 470, 250-254, doi:10.1038/nature09751.

Son, S. W., and Coauthors, 2008: The impact of stratospheric ozone recovery on the Southern Hemisphere westerly jet. Science, 320, 1486-1489, doi:10.1126/science.1155939.

Taylor, K. E., R. J. Stouffer, and G. A. Meehl, 2012: An overview of CMIP5 and the experiment design. Bull. Amer. Meteor. Soc., 93, 485-498, doi:10.1175/BAMS-D-11-00094.1.

Tett, S. F. B., and Coauthors, 2002: Estimation of natural and anthropogenic contributions to twentieth century temperature change. J. Geophys. Res., 107, 4306, doi:10.1029/2000JD000028.

Thompson, D. W. J., and S. Solomon, 2002: Interpretation of recent Southern Hemisphere climate change. Science, 296, 895-899, doi:10.1126/science.1069270.

Tomas, R. A., C. Deser, and L. Sun, 2016: The role of ocean heat transport in the global climate response to projected Arctic sea ice loss. J. Climate, 29, 6841-6859, doi:10.1175/JCLI-D-15-0651.1.

Trenberth, K. E., and A. Solomon, 1994: The global heat balance: Heat transports in the atmosphere and ocean. Climate Dyn., 10, 107-134, doi:10.1007/BF00210625.

— D. P. Stepaniak, and J. M. Caron, 2002: Accuracy of atmospheric energy budgets from analyses. J. Climate, 15, 3343-3360, doi:10.1175/1520-0442(2002)015<3343:AOAEBF>2.0.CO;2.

Trossman, D. S., J. B. Palter, T. M. Merlis, Y. Huang, and Y. Xia, 2016: Large-scale ocean circulation-cloud interactions reduce the pace of transient climate change. Geophys. Res. Lett., 43, 3935-3943, doi:10.1002/2016GL067931.

van der Swaluw, E., S. S. Drijfhout, and W. Hazeleger, 2007: Bjerknes compensation at high northern latitudes: The ocean forcing the atmosphere. J. Climate, 20, 6023-6032, doi:10.1175/ 2007JCLI1562.1.
Venegas, S. A., and M. R. Drinkwater, 2001: Sea ice, atmosphere and upper ocean variability in the Weddell Sea, Antarctica. J. Geophys. Res., 106, 16747-16 765, doi:10.1029/ 2000JC000594.

White, W. B., and R. G. Peterson, 1996: An Antarctic circumpolar wave in surface pressure, wind, temperature and sea-ice extent. Nature, 380, 699-702, doi:10.1038/380699a0.

Winton, M., 2003: On the climatic impact of ocean circulation. J. Climate, 16, 2875-2889, doi:10.1175/1520-0442(2003)016<2875: OTCIOO $>2.0 . \mathrm{CO} ; 2$.

_ , R. Hallberg, and A. Gnanadesikan, 1998: Simulation of density-driven frictional downslope flow in $Z$-coordinate ocean models. J. Phys. Oceanogr., 28, 2163-2174, doi:10.1175/ 1520-0485(1998)028<2163:SODDFD $>2.0 . C O ; 2$.

Wood, R., and C. S. Bretherton, 2006: On the relationship between stratiform low cloud cover and lower-tropospheric stability. J. Climate, 19, 6425-6432, doi:10.1175/JCLI3988.1.

Yang, S., E. Galbraith, and J. Palter, 2014: Coupled climate impacts of the Drake Passage and the Panama Seaway. Climate Dyn., 43, 37-52, doi:10.1007/s00382-013-1809-6.

Yuan, X. J., and D. G. Martinson, 2000: Antarctic sea ice extent variability and its global connectivity. J. Climate, 13, 1697-1717, doi:10.1175/1520-0442(2000)013<1697:ASIEVA>2.0.CO;2.

_, M. A. Cane, and D. G. Martinson, 1996: Cycling around the South Pole. Nature, 380, 673-674, doi:10.1038/380673a0.

Zanowski, H., R. Hallberg, and J. L. Sarmiento, 2015: Abyssal ocean warming and salinification after Weddell polynyas in the GFDL CM2G coupled climate model. J. Phys. Oceanogr., 45, 2755-2772, doi:10.1175/JPO-D-15-0109.1.

Zelinka, M. D., and D. L. Hartmann, 2012: Climate feedbacks and their implications for poleward energy flux changes in a warming climate. J. Climate, 25, 608-624, doi:10.1175/ JCLI-D-11-00096.1.

Zhang, R., S. M. Kang, and I. M. Held, 2010: Sensitivity of climate change induced by the weakening of the Atlantic meridional overturning circulation to cloud feedback. J. Climate, 23, 378389, doi:10.1175/2009JCLI3118.1.

Zhang, Y.-C., and W. B. Rossow, 1997: Estimating meridional energy transports by the atmospheric and oceanic general circulations using boundary fluxes. J. Climate, 10, 2358-2373, doi:10.1175/1520-0442(1997)010<2358:EMETBT>2.0.CO;2. 